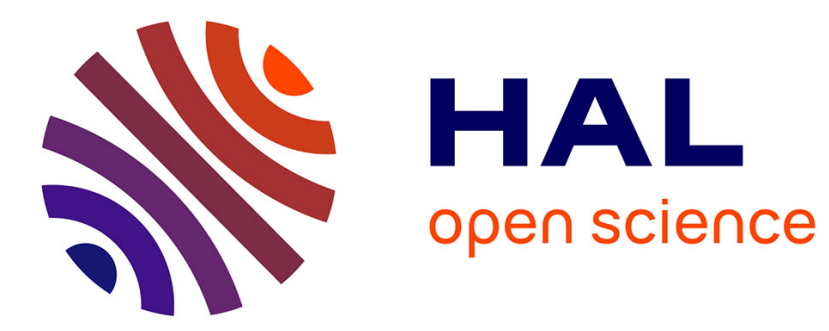

\title{
The relationship between the cutting speed, tool wear, and chip formation during Ti-5553 dry cutting
}

\author{
Vincent Wagner, Maher Baili, Gilles Dessein
}

\section{To cite this version:}

Vincent Wagner, Maher Baili, Gilles Dessein. The relationship between the cutting speed, tool wear, and chip formation during Ti-5553 dry cutting. International Journal of Advanced Manufacturing Technology, 2015, vol.76 ( $\mathrm{n}^{\circ}$ 5-8), pp. 893-912. 10.1007/s00170-014-6326-1 . hal-01635626

\section{HAL Id: hal-01635626 \\ https://hal.science/hal-01635626}

Submitted on 15 Nov 2017

HAL is a multi-disciplinary open access archive for the deposit and dissemination of scientific research documents, whether they are published or not. The documents may come from teaching and research institutions in France or abroad, or from public or private research centers.
L'archive ouverte pluridisciplinaire HAL, est destinée au dépôt et à la diffusion de documents scientifiques de niveau recherche, publiés ou non, émanant des établissements d'enseignement et de recherche français ou étrangers, des laboratoires publics ou privés. 


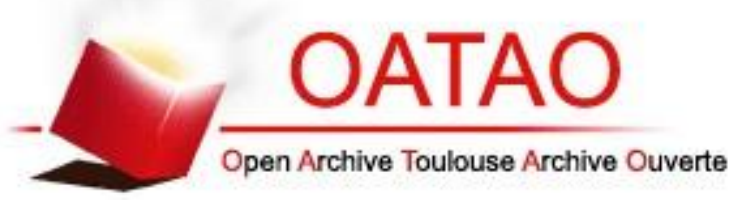

Open Archive Toulouse Archive Ouverte (OATAO)

OATAO is an open access repository that collects the work of Toulouse researchers and makes it freely available over the web where possible.

This is an author-deposited version published in: http://oatao.univ-toulouse.fr/ Eprints ID: 12014

Identification number: DOI: 10.1007/s00170-014-6326-1

Official URL: http://dx.doi.org/10.1007/s00170-014-6326-1

\section{To cite this version:}

Wagner, Vincent and Baili, Maher and Dessein, Gilles The relationship between the cutting speed, tool wear, and chip formation during Ti-5553 dry cutting. (2014) International Journal of Advanced Manufacturing Technology, vol.76 $\left(\mathrm{n}^{\circ}\right.$ 5-8). pp. 893-912. ISSN 0268-3768

Any correspondence concerning this service should be sent to the repository administrator: staff-oatao@inp-toulouse.fr 


\title{
The relationship between the cutting speed, tool wear, and chip formation during Ti-5553 dry cutting
}

\author{
Vincent Wagner • Maher Baili • Gilles Dessein
}

\begin{abstract}
Over the past several years, titanium alloys have been increasingly used in aeronautics. However, they are considered to have poor machinability. The Ti-5553 nearbeta titanium alloy is used in aeronautics to replace Ti-64 and for the production of structural parts, such as landing gears. Due to the low thermal properties and the high mechanical properties presented in this work, this alloy is considered difficult to machine. This work is devoted to understanding the relationship between the chip formation, the cutting process, and the tool wear. The first section studies the evolution of the tool wear. The tests show that tool wear occurs in three steps mainly due to the cutting process and the chip formation. To clarify these points, a section is dedicated to the chip formation and cutting processes. An analytical model is also used to quantify stresses, temperatures, and friction inside the workpiece material and at the tool/chip interface. Chip formation is commonly studied using a tool without wear, which can affect the cutting tool geometry. To verify chip formation and the cutting process during machining, a section describes the chip formation and the cutting processes using worn tools.
\end{abstract}

Keywords Ti-5553 - Titanium alloys · Dry turning - Tool wear $\cdot$ Cutting conditions $\cdot$ Chip formation

\section{Introduction}

The reduction of mass and maintenance costs are important challenges in the aeronautical industry. This evolution has,

\author{
V. Wagner $(\bowtie) \cdot$ M. Baili · Gilles Dessein \\ Université de Toulouse, INP/ENIT, LGP, 47 avenue d'Azereix, \\ BP 1629, 65016 Tarbes Cedex, France \\ e-mail: vincent.wagner@enit.fr
}

for the first time, affected the fuselage, where composite materials are frequently used. This evolution has included other parts of the aircraft, such as the landing gear, which require the use of high-performance materials. For this reason, the Ti-5553 alloy is used in Boeing 787 landing gears. This new titanium alloy has a good combination of strengthto-weight ratio and resistance to corrosion. However, the first tests classified the Ti-5553 as a difficult to cut material. Moreover, to reduce the costs of production and ensure that the process is environmentally safe, the aeronautical manufacturers moved to dry cutting. The effect of this change on Ti-5553 cutting is unknown. In the current literature, the most common titanium alloy studied is Ti-64, where the main wear modes are abrasion and adhesion. In [1], Ti-5553 and Ti-64 machinability are compared. They observed flank wear and notch wear in both materials and explained that the poor machinability of Ti-5553 is defined by the concentration of alpha gene elements. However, this work studies the machinability of untreated Ti-5553. Titanium alloy machinability is generally considered to be poor because of the inherent mechanical and chemical properties of the alloys. Moreover, the titanium alloy $\mathrm{Ti}-6 \mathrm{Al}-4 \mathrm{~V}$ produces highly serrated chips over a wide range of cutting speeds. During its formation, the chip is divided into segments that are very thin with localized shear strain. The instability of the plastic deformation may also be accompanied by several physical and metallurgical changes. According to [1] and [2], the chip formation partially explains the tool wear. Moreover, due to the low machinability, the cutting speeds are often low, which generates some non-segmented chips that are difficult to remove.

The current literature covers titanium machinability, but Ti-64 is frequently the only titanium alloy studied. The motivation of the present investigation is a contribution to the understanding of tool wear in Ti-5553 machines using 
Table 1 Ti-5553 and Ti-64 composition

\begin{tabular}{lllll}
\hline Elements & Aluminum & Molybdenum & Vanadium & Chromium \\
\hline Ti5553 & 5 & 5 & 5 & 3 \\
Ti64 & 6 & - & 4 & - \\
\hline
\end{tabular}

dry cutting, the chip formation and the relationship between these factors. After a study about the material and the experimental set-up is presented, the evolution of tool wear is studied with respect to the cutting forces. The second part is devoted to the chip formation. The first part shows very low thermal properties and some high mechanical properties. However, chip formation in Ti-5553 machining is still unknown. To understand the cutting process (temperature, strain, stress and friction) and its effect on chip formation, an analytical model is used. The last section studies the relation between chip formation, the cutting process and the tool wear. The tool wear and its effect on the cutting tool geometry are not often discussed. A study on tool wear, chip formation and the cutting process will be presented in this section.

\section{Titanium alloys presentation}

The tests were carried out on heat-treated Ti-5553 titanium alloy (supplied by Messier Dowty). Its chemical composition is given in Table 1. The Ti-5553 is a beta-metastable structure and belongs to the near-betaalloys family of titanium; Ti-64 is alpha-beta titanium. Its metastable property is described by the chemical composition [1].

The metastable elements appear during solution heat treatment and after deformation under stress. The alphagene concentration is a function of the temperature of the solution and the cooling rate. The titanium presented in this work is a heat-treated and forged material and, consequently, different from the material studied by [1] The heat treatment is shown in Fig. 1. It is divided into three parts. First, the material is heated to $800{ }^{\circ} \mathrm{C}$ for $4 \mathrm{~h}$. The titanium is cooled. This operation can be compared to quenching. Finally, the material is aged at $600{ }^{\circ} \mathrm{C}$ for $8 \mathrm{~h}$.

The titanium alloys show a large variety of microstructures function of the alloy composition, the heat treatment, and the strain created in the alloy. For titanium alloys, the different added elements have a large impact on the phase stability. The classification of elements is defined according to their affinity for the alphagene and betagene phases. $\mathrm{Al}, \mathrm{O}, \mathrm{N}, \mathrm{C}$, and $\mathrm{B}$ are alphagene elements. $\mathrm{Mo}, \mathrm{V}, \mathrm{Nb}$, and Ta stabilize the phase, and the eutectoid elements $(\mathrm{Mn}, \mathrm{Fe}, \mathrm{Cr}, \mathrm{Co}, \mathrm{W}, \mathrm{B}, \mathrm{Ni}, \mathrm{Cu}, \mathrm{Au}, \mathrm{Ag}$, and $\mathrm{Si})$ increase the intermetallic order. For the Ti-5553 studied, the microstructure is globular or equiaxed. A spectral analysis shows the difference between the two phases. The $\alpha$ phase shows the lowest concentration of aluminium. During the heat treatment, a combination of the $\alpha$ and $\beta$ phases generates some nodules, which will coalesce during the tempering. This tempering also generates fine $\alpha$ precipitates in the $\beta$ matrix. The Ti-5553 microstructure is shown in Fig. 2.

The titanium alloys can be classified according to the $\mathrm{Al}$ and Mo equivalent values. The $\mathrm{Al}$ and Mo equivalent values show the properties of titanium alloys according to the equations shown in Table 2. The $A l_{e q}$ value shows the ability of the titanium alloys to obtain a given hardness, while the $M o_{e q}$ value indicates the capacity to obtain a certain tensile strength. For Ti-5553, the Mo equivalent is higher than the Ti-64 value, whereas the Al equivalent value is lower than the Ti-64 value. Therefore, the Ti-5553 alloy has a higher capacity for tensile stress, but its hardness could be lower. These first observations can show the difficulty in machining Ti-5553 compared to traditional titanium alloys. This observation correlates with the work of [1].

Fig. 1 Ti5553 heat treatment

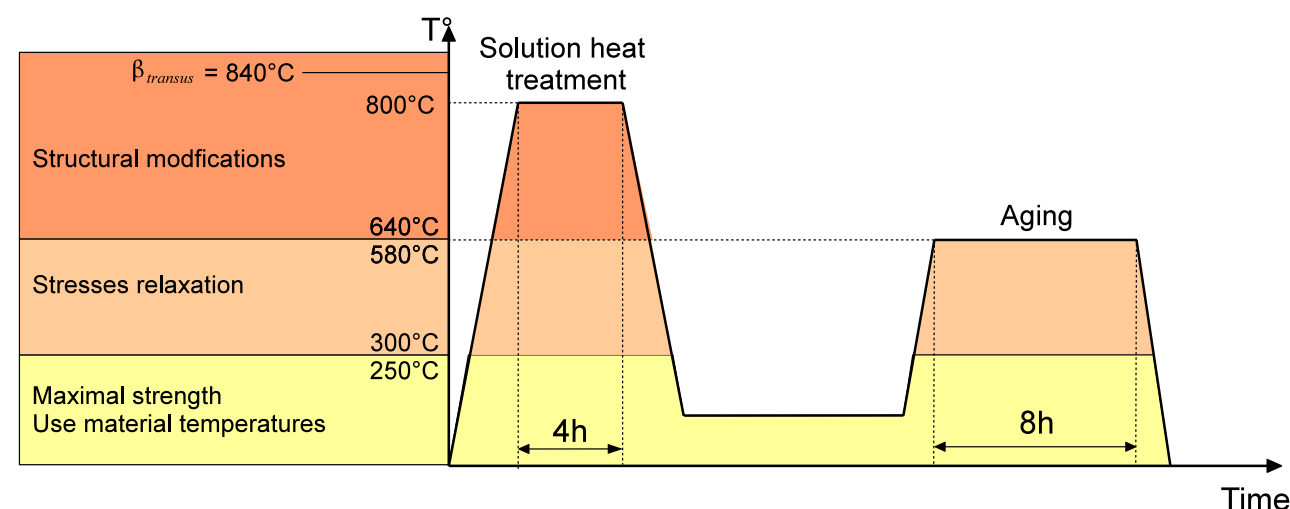




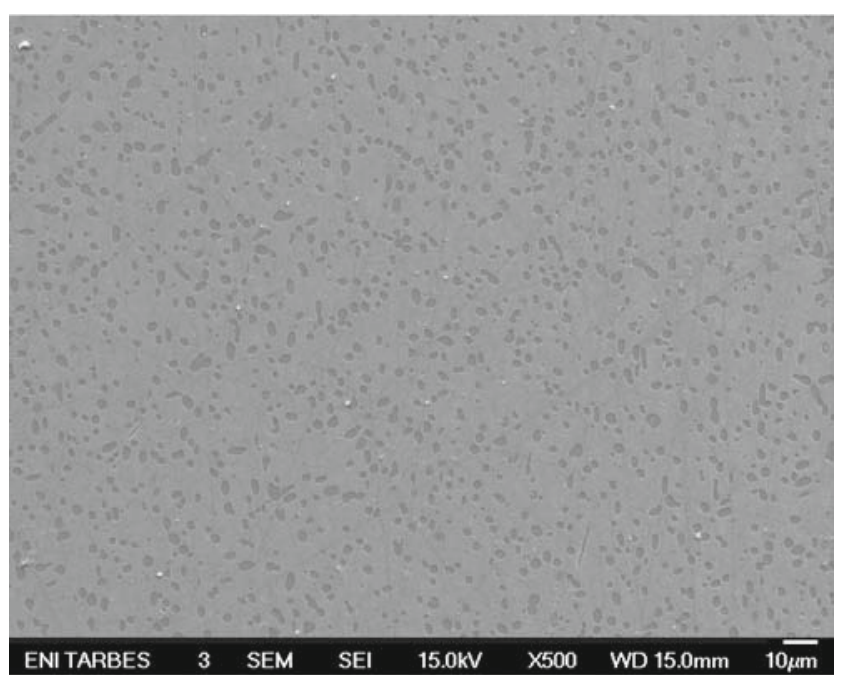

Fig. 2 The microstructure of the Ti-5553 alloy

They observed that the $\alpha$ phase concentration of Ti-64 was $80 \%$ while the Ti-5553 concentration was $20 \%$, and they explained the low Ti-5553 machinability using the betagene concentration.

\subsection{Titanium thermal properties}

The mechanical and physical properties determine the cutting process and, consequently, the material machinability. Some articles claimed that $80 \%$ of the heat generated during machining is absorbed by the tool compared to steel machining where $40 \%$ of heat generated is transferred into the tool [3]. He explained these phenomena using the difference between the tool and titanium thermal properties. This part of the work focused on the thermal properties (specific heat and thermal conductivity) and their effects on the cutting process. The physical properties of titanium alloys were also compared to basic steel [3].

The specific heat $(S)$ characterizes the capacity of a material to accumulate heat. The specific heats for Ti-5553, Ti-64, and steel are shown in Fig. 4. For all materials, the specific heat increases with the temperature. In the range of 100 to $350{ }^{\circ} \mathrm{C}$, the Ti- 64 specific heat is the greatest. At higher temperatures, the Ti-5553 value becomes the largest.

The thermal conductivity $(K)$ illustrates the capacity of an alloy to transfer heat via conduction. In the titanium

Table 2 Aluminum and molybdenum equivalent for Ti-64 and Ti-5553

\begin{tabular}{lll}
\hline Titanium alloy & $A l_{e q}$ & $M o_{e q}$ \\
\hline Ti5553 & 6.3 & 14.3 \\
Ti64 & 7 & 2.5 \\
\hline
\end{tabular}

alloys, the thermal conductivity increases with the temperature. Their values remain low, and importantly, they remain lower than the steel values. In contrast to titanium, the steel values decrease as the temperature increases, and they are always higher than the alloys (Fig. 3). Steel conducts heat better than the titanium alloys. Due to the higher thermal conductivity of the tools, the heat is transferred into the tool and may cause oxidation or a decrease in the mechanical properties.

\subsection{Mechanical properties}

Based on tensile stress tests, the Ti-64 and Ti-5553 mechanical properties at different temperatures are compared (Fig. 3). Tensile specimens with 8-mm diameter and 30-mm gauge length were machined. Tensile tests were carried out with a strain rate of $1 \times 10^{-3}$ by using an Instron 1342 testing machine equipped with a radiant heating enclosure.

At room temperature, the Young's modulus are the same; therefore, their stiffnesses are equal and significantly lower than steel $(200 \mathrm{GPa})$. The tensile behaviors of both alloys are similar. The tensile yield stress and the ultimate tensile stress for Ti-5553 is more than $30 \%$ higher than the Ti-64 values. In the Ti-5553, a limited plastic range and a high yield rate are observed. Concerning the elongation, there is a significant difference between the both titanium alloys studied. Compared to Ti-64, the Ti-5553 ductility is very low. To understand the titanium alloy behavior, some further tensile tests at different temperatures $\left(400\right.$ and $900{ }^{\circ} \mathrm{C}$ ) were conducted. There is a significant difference between the titanium alloys as the temperature increases. The Ti-64 mechanical properties reduce to approximately $60 \%$ of its maximum strength at $900{ }^{\circ} \mathrm{C}$. There is a smaller variation in the mechanical properties of Ti-5553, with a reduction of $30 \%$ at $900{ }^{\circ} \mathrm{C}$. These differences and especially the ability of Ti-5553 to preserve its mechanical properties at high temperatures may be one of the explanations for the low machinability. It should also be noted that both materials have low ductility, which remains constant with increasing temperature. For the Ti-5553, a modification of the plastic behavior with the yield rate is observed. These observations are useful in specific titanium alloy uses. Indeed, the mechanical properties remain high even at $400{ }^{\circ} \mathrm{C}$, and at high temperatures, the Ti-5553 alloy behaviors are extremely high.

\section{Experimental set-up}

Some cutting experiments were carried out using a computerized numerical control (CNC Ernault Somua) lathe. All tests were carried out using dry cutting. To eliminate the heterogeneity produced during heat treatment, the samples 
Fig. 3 Evolution of the mechanical properties of Ti-64 and Ti-5553

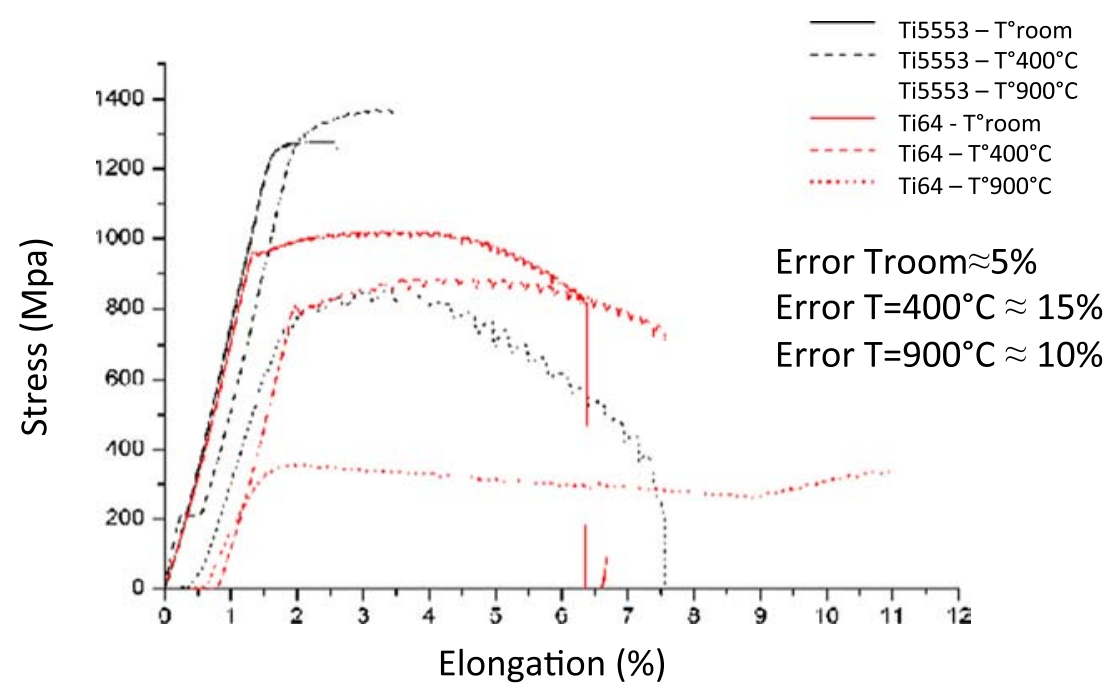

were machined to thicknesses ranging from 5 to $10 \mathrm{~mm}$. The cutting conditions used during these tests are given in Table 3.

A dynamometer platform was used for the cutting force measurements (Kistler 9263-A). The signals were analyzed using the Dynoware software. To determine the tool wear, some images were taken using the white-light interferometer technique with an Optical Metrology Module Wyko. The Veeco interferometer uses light reflected from a reference mirror that is combined with light reflected from the surface under analysis to produce a series of interference fringes. The reference arm of the interferometer moves vertically to scan the surface at varying heights. A camera is used to capture frames of the interference data, which is analyzed using a series of computer algorithms to produce a topological map of the tool. The cutting forces will be divided into two components: the $F_{c}$ component is collinear with the cutting direction, while the $F_{t}$ component is in the feed direction.
The cutting tool material is tungsten carbide with a TiAlN coating. The chemical composition of this material is shown in Fig. 5. The rake angle is $12^{\circ} \mathrm{C}$, the edge hone radius is $0.04 \mathrm{~mm}$, and the rake angle is $5{ }^{\circ} \mathrm{C}$.

To analyze the samples, some chips were collected and embedded in resin. The lateral section was polished before etching with Kroll solution. The chip serration indicated adiabatic shear banding, which is easily triggered in titanium alloys.

\section{Tool wear analyze}

The aim of this section is the highlighting of the tool failure modes generated during Ti-5553 dry cutting. The cutting tool damage occurs in three steps.

The first step is a modification of the cutting tool geometry and it is similar to crater wear (Fig. 6). It occurs close to

Fig. 4 Thermal properties

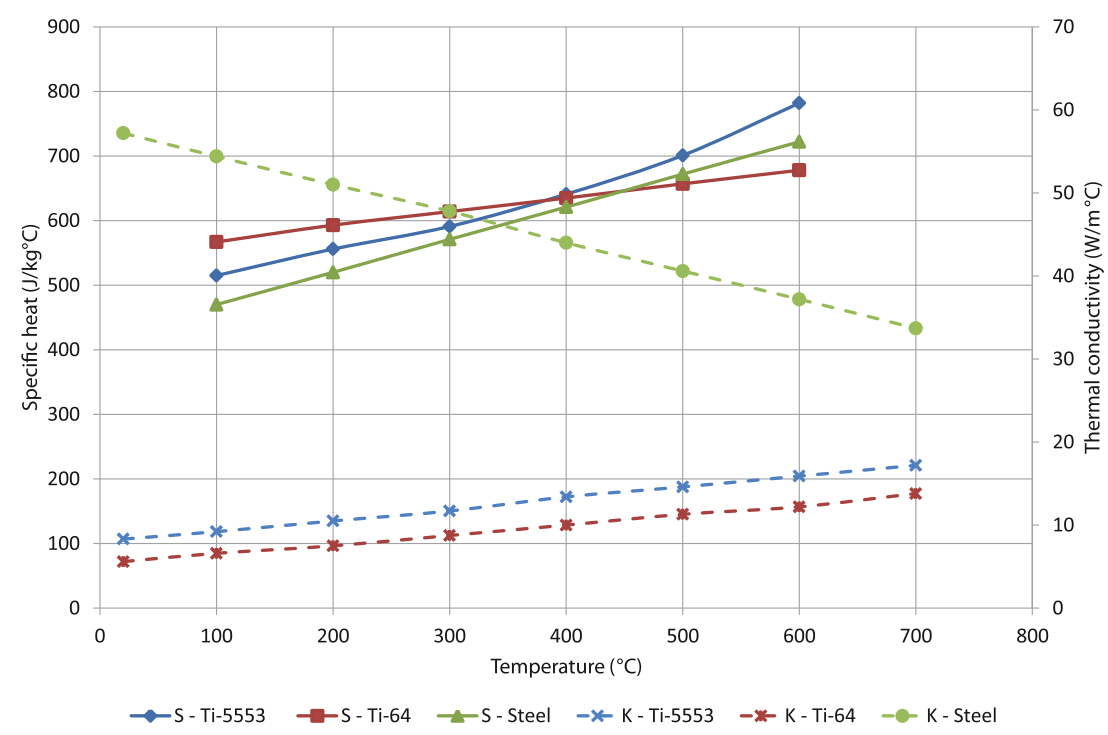


Table 3 Experimental range of cutting conditions

\begin{tabular}{ll}
\hline Cutting speed & $35^{\mathrm{m}} / \min <V_{c}<65^{\mathrm{m}} / \min$ \\
Uncut chip thickness & $t_{u}=0.2 \mathrm{~mm}$ \\
Radial depth & $a_{p}=3 \mathrm{~mm}$ \\
\hline
\end{tabular}

the cutting edge, and its width is approximately two times the uncut chip thickness (Fig. 6. On the rake face, a thickness equal to the coating thickness is removed. The first mode represents approximately $5 \%$ of tool life. This wear mechanism has been observed by [4]. They state that during titanium alloys machining, some adhesion occur on the rake face. They also observed that diffusion is the most active wear mechanism, which generates some tearing of the tool material.

This first mode can be explained using a nearly segmented chip and by the abrasive cutting process [2]. The chip friction on the rake face draws away coating particles. The chip morphology can be explained by the high yield stress of Ti-5553 and the high temperature. Indeed, the stress in the primary shear zone is always lowest than the ultimate tensile strength. According to [1], the nonsegmented chips and high frequency of the shearing bands explain the rapid tool wear. According to [5], the low titanium machinability is caused by the instability of chip formation, which results in a segmented (or cyclical) chip.

During the second mode of tool wear or during normal wear, the cutting tool geometry is unchanged. Because, the coating is removed during the first mode, the machining is consequently performed without a coating. The effect of the coating is then negligible during 80 of the tool life. This observation supports the conclusions made by [6] in which

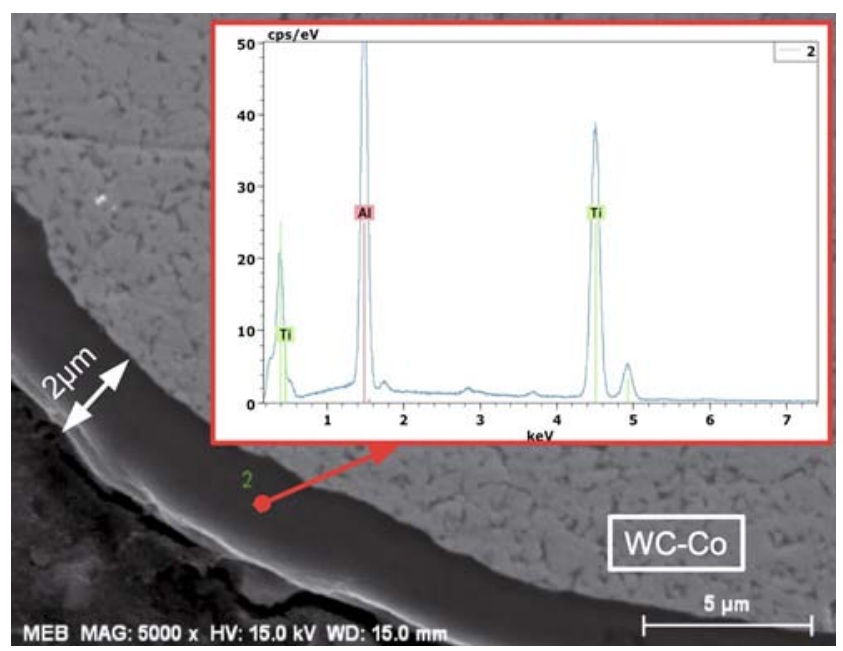

Fig. 5 Tool material they state that the best solution for titanium machining is an uncoated tool of $\mathrm{K}$ grade.

During the last mode, two types of modifications have been observed on the tool. The first phenomenon is a builtup edge, and the second is a failure of the cutting edge. The built-up edge width and the radial depth are the same (3 mm) (Fig. 7). A built-up edge generally appears during the machining of ductile materials. Yet, the Ti-5553 elongation is less than 5. Fang et al. [7] claim that the built-up edge is due to the cutting temperature and friction between the tool and chips on the rake face. In Ti-5553 machining, the cutting temperature is often very high, increasing the ductility and forming the built-up edge. The cutting edge failure influences the depth of the cut (Fig. 7).

The last mode is the first in a series of steps leading to the tool edge failure. The abrasive chips cause a modification of the cutting tool geometry. This geometrical modification generates an increase in the cutting forces and, consequently, in the cutting temperatures. The workpiece material is also more ductile, and the stresses at the toolchip interfaces increase generating a built-up edge (BUE). If the cutting forces caused by the BUE are too high, the cycle of degradation is accelerated, which leads to a failure of the cutting edge.

In the current literature, the types of tool wear observed during titanium alloy machining are crater, notch, and flank wear. However, contrary to [1] who studied untreated Ti5553 , flank wear was not observed during these tests, which can be explained by the difference between the treated and untreated Ti-5553. The ductility of treated Ti-5553 was lower, and the radial component of the machining was higher. The machined surface was never in contact with the flank face due to the low elastic recovery. Consequently, flank wear did not occur. For some coated tools, burn marks were observed on the flank face. The high temperatures observed during titanium alloy machining caused this phenomenon.

To complete the understanding of tool wear and to define its effect on the cutting tool, SEM and an energy dispersive $\mathrm{X}$-ray spectroscopy have been performed on the rake face (Fig. 8). This analysis was carried out before the edge failure when the built-up edge was still present. First, the deposit on rake face was Ti-5553 titanium alloy. Indeed, aluminum, titanium, and molybdenum were observed. Below the contact length, some tungsten carbide was observed when the Ti-5553 layer is not present. The abrasion phenomenon observed using interferometry was supported. The coating seems to not be affected above the contact length. Indeed, some aluminum from the coating (TiAlN) was still present. In the titanium alloy, the $\alpha$ nodules presented in the previous section did not appear. These modifications were due to the high temperatures and the high deformations incurred by the material at the tool chip interface. 
Fig. 6 The first mode of tool wear observed using the interferometry technique

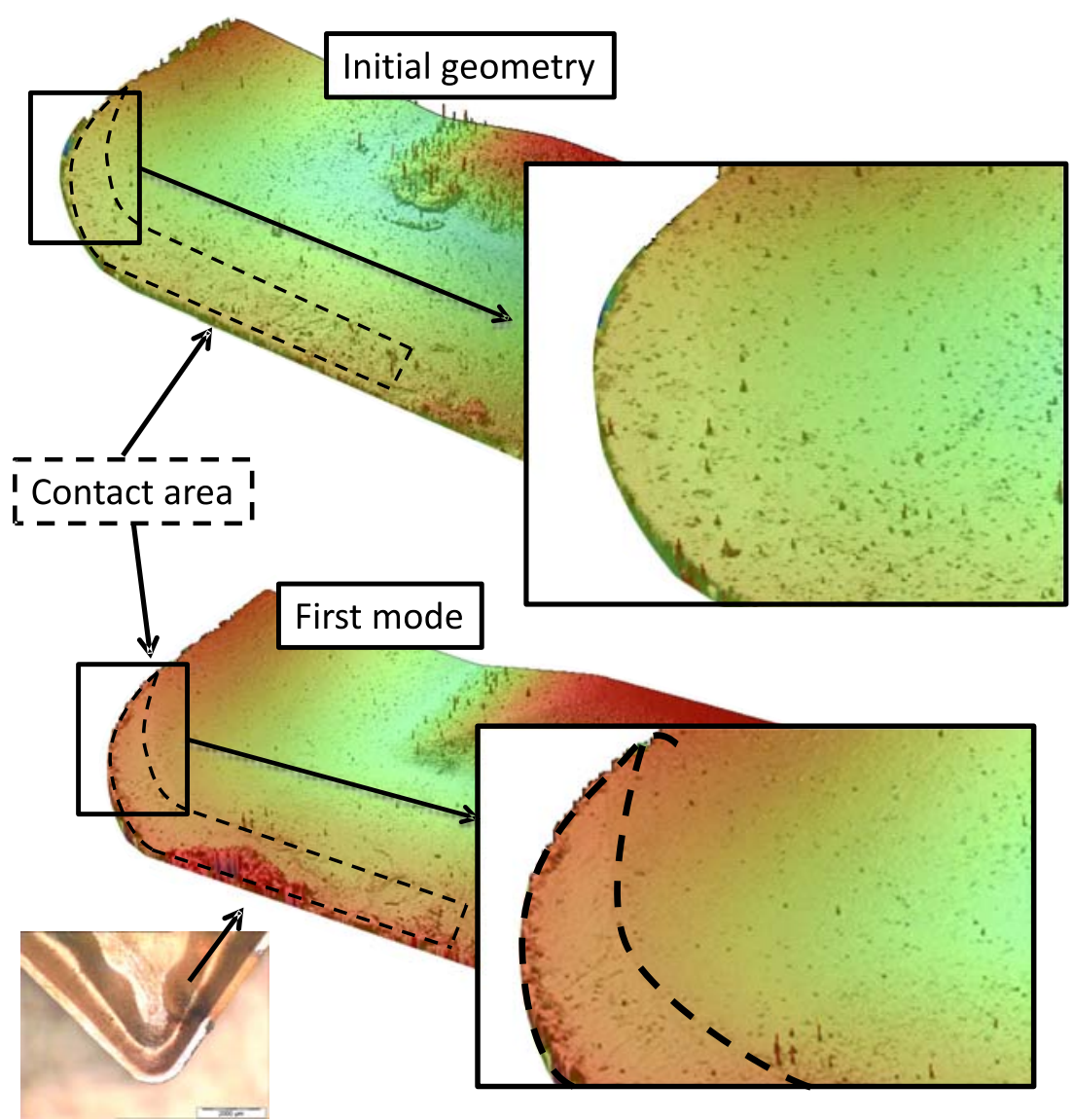

The tool wear and, especially, its monitoring require a measurable criterion. There are well-known criteria that inform on the level of tool wear, and Taylor's law is used to describe this wear. The French standard and [1] suggest the monitoring of the flank wear or the crater wear width, which are functions of time. However, the first observations do not allow its measurement or its monitoring. It is possible to summarize the different interactions between the wear and the cutting process (Fig. 9). The cutting process is a function of the cutting geometry. For example, a modification of the rake angle may result in a reduction of the cutting temperature. The tool wear pattern is a generated by the cutting process. The temperature rise causes diffusion or an increase in the friction at the tool-chip interface, which can generate crater wear. There is a link between each element, and the criteria must be chosen out of these elements.

In order to validate criteria as cutting forces, an acquisition has been made for each tests. The choice of cutting forces compared to cutting temperatures has been validated through another tests ([8]). In order to measure cutting temperatures, the Actarus's system has been used. The temperatures are measured with a thermocouple located close to cutting edge. However, the insert strength is reduced by the thermocouple limiting the time acquisition at $8 \mathrm{~s}$.
Figure 10 shows the cutting forces components according the tool wear. There is a good correlation between cutting forces and tool wear. It is possible to observe the three modes (first mode, normal wear, and the last mode) observed in the previous section. At the end of the first step (corresponding to crater wear), both cutting force components increase linearly and continuously. In the second step (called normal wear), a stabilization of the cutting forces was observed, which corresponds to approximately $90 \%$ of the tool life. In this phase, the cutting force dispersion is approximately $5 \%$. The last step is the tool edge failure, where the damage is rapid and its effect seems very important to the cutting process. The result of the cutting force increased by $20 \%$ compared to the previous test. Another important point is the evolution of the $F_{t}$ component. During the first mode of tool wear, the modification of the cutting geometry generated an increase in the $F_{t}$ component.

During normal wear, Ft increased for the first two tests (50 to $100 \mathrm{~mm}$ of machining) and decreased during the following six tests. This evolution is explained by the effect of the cutting edge geometry on the cutting temperature. Indeed, the degradation of the cutting geometry led to a temperature increase and consequently a reduction in 


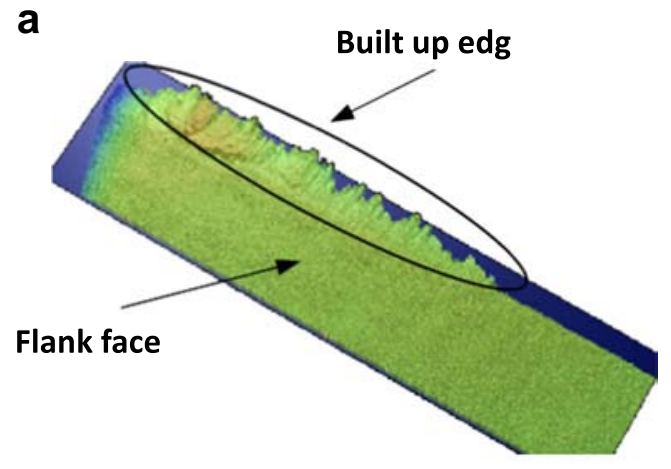

b

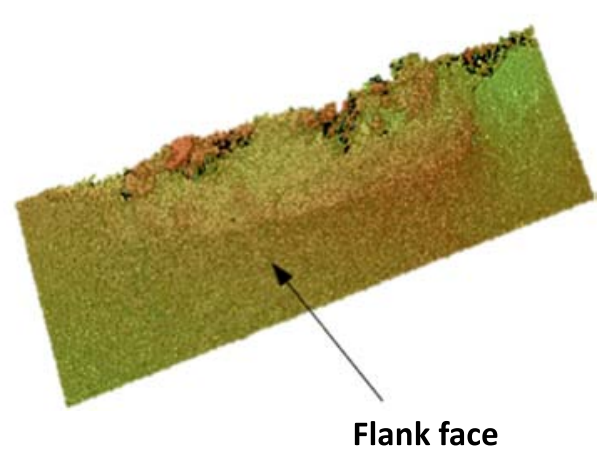

Fig. 7 Built up edge and edge failure

the mechanical resistance. While during the last mode, $F_{t}$ became higher than $F_{c}$. The edge failure observed was then too great, and the rake angle became negative.

\section{Cutting forces model}

The cutting process generates some friction, stress, and temperature that occur in the workpiece material, cutting

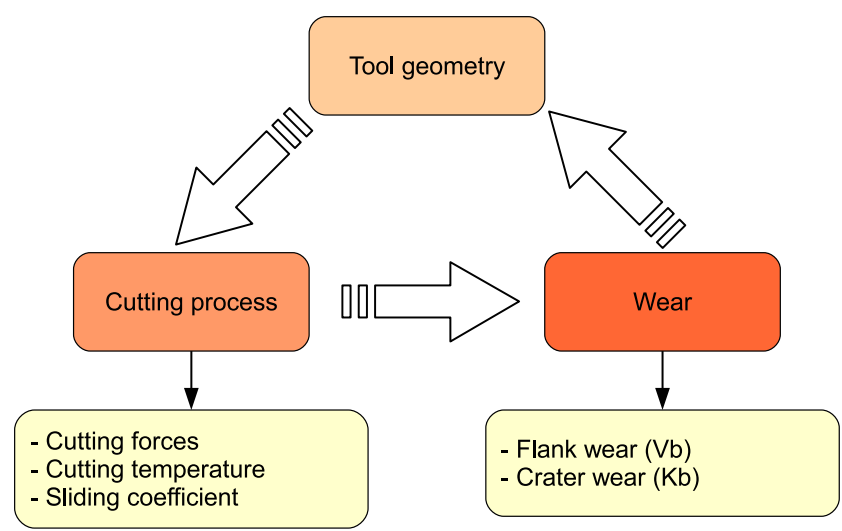

Fig. 9 Summary of the wear effect on the cutting process

tool, and chips. To understand and to quantify their levels, a model is also required. Ozel and co-workers compared some analytical models for Ti-64 machining ([9]). The study is based on the cutting forces and cutting temperatures. The difference between the values from the analytical models and the FEM analysis was also studied. He concluded that the best model is Oxley's model [10] (Fig. 11).

First, the model was defined for orthogonal cutting. The model is also based on the hypothesis that the primary shear zone is limited between two parallel plans. The mean plan is the symmetric plan and is assimilated into the plan defined by Merchant. Some strain appears at the secondary shear zone (tool/chip interface), which generates sticking on the rake face. The secondary shear zone and the mean plan are the stress plane and maximal strain plane. The temperature is constant in the mean plane.
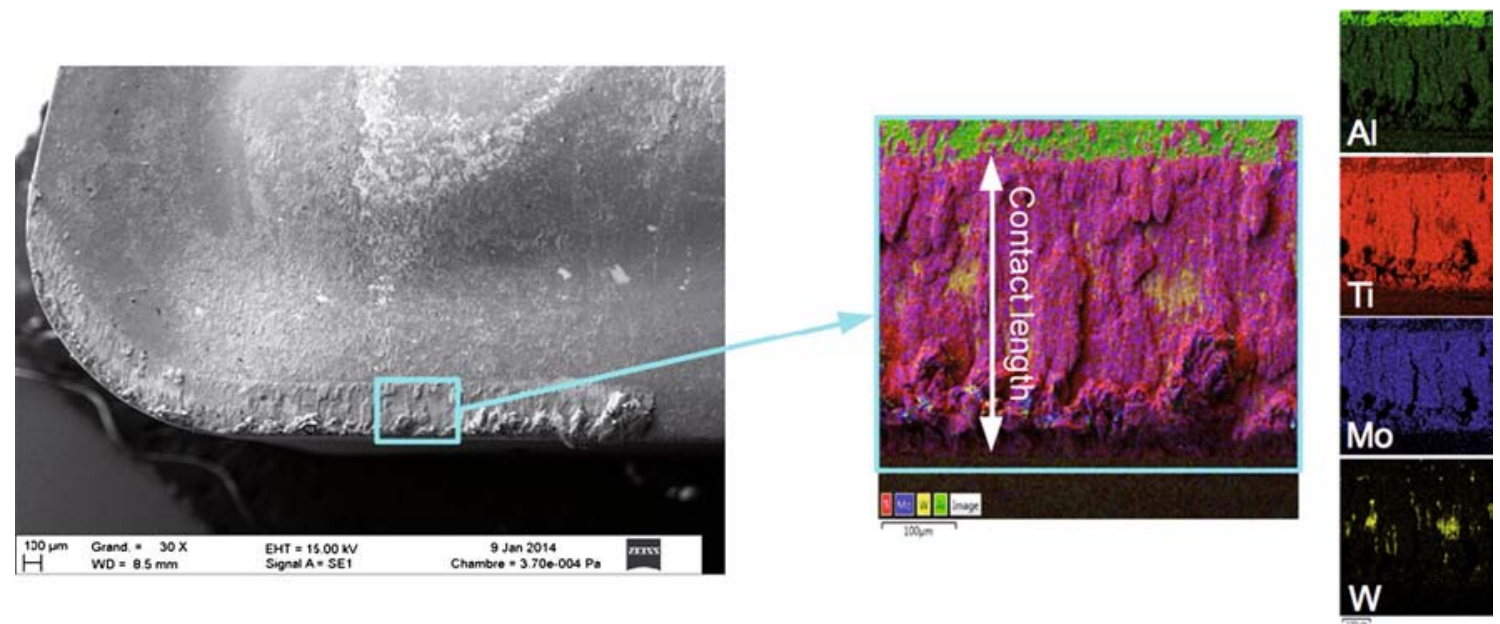

Fig. 8 SEM and EDS analysis of tool wear 


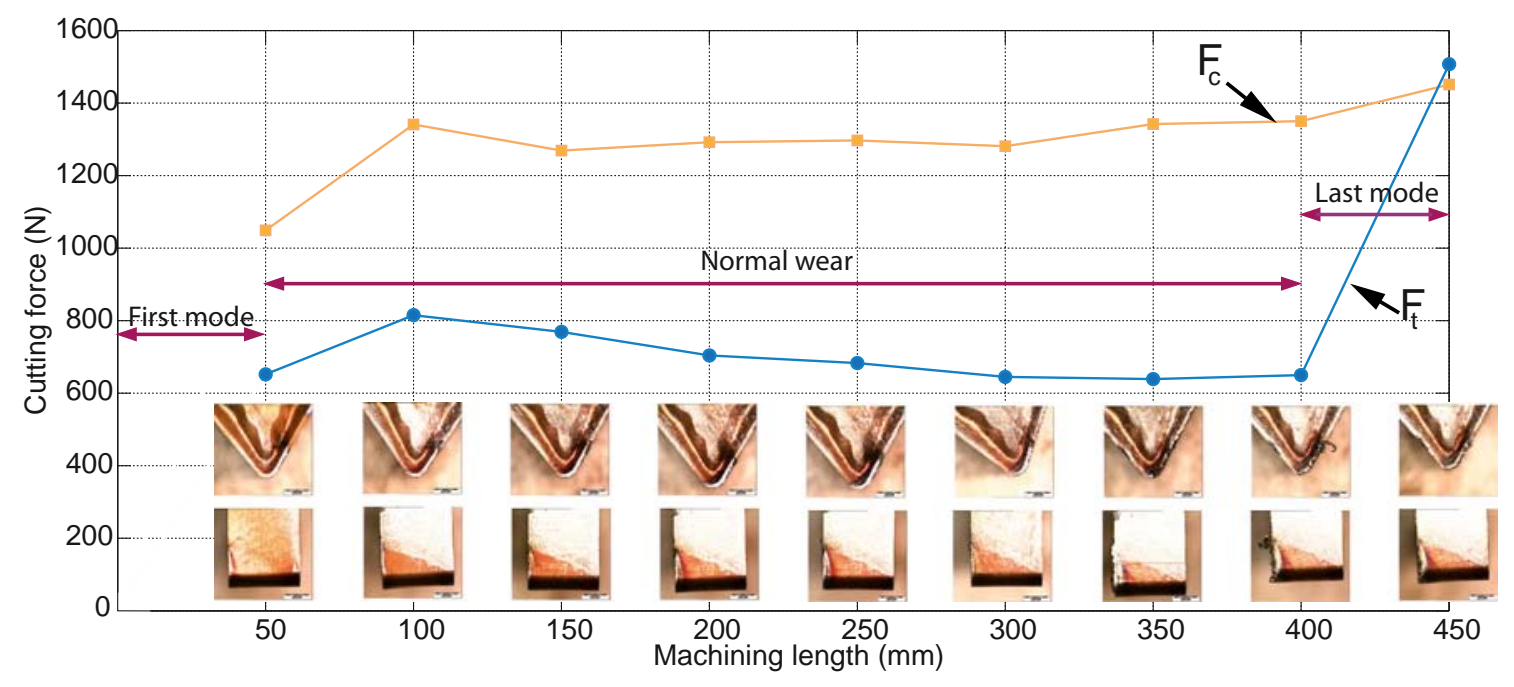

Fig. 10 Cutting forces according to tool wear

$V_{s}$ is the velocity along shear plane and is defined as

$V_{s}=\frac{V_{c} \cos \alpha}{\cos (\phi-\alpha)}$

$\phi$ is the shear angle and is solved according to Merchant's study:

$\phi=\tan ^{-1}\left(\frac{\frac{t_{u}}{t_{c}} \cos \alpha}{1-\frac{t_{u}}{t_{c}} \sin \alpha}\right)$

However, Komanduri shows that the Merchant formulation shear angle defined for continuous chip formation does not work for titanium alloys [11]. Consequently, the shear angle was measured in each test (Fig. 12).

Fig. 11 The Oxley model
The shear force is calculated from the measured cutting force components $\left(F_{c}\right.$ and $\left.F_{t}\right)$ :

$F_{s}=F_{c} \sin \phi-F_{t} \cos \phi$

The shear stress in the primary zone is defined from $F_{S}$ and similar to Oxley, it stays the same on the plane $a b$ :

$k_{a b}=\frac{F_{s} \sin \phi}{t_{u} a_{p}}$

To define the cutting temperature, Oxley and co-workers have used the Boothroyd model ([12]). In the primary zone, the temperature rise was calculated as follows:

$T_{a b}=T_{0}+\triangle T_{a b}$

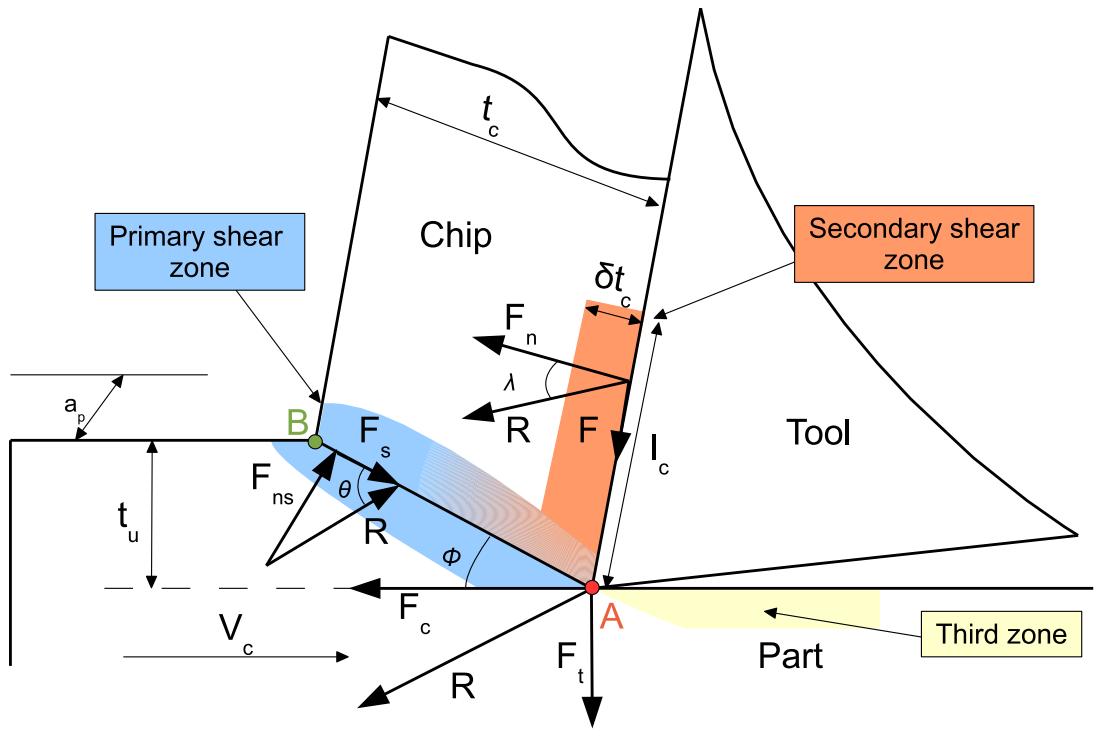




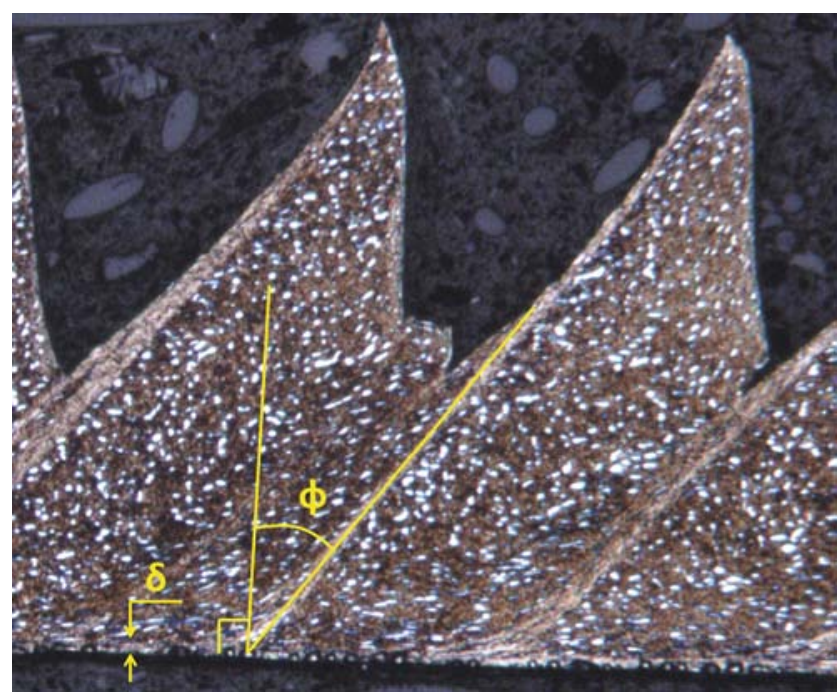

Fig. $12 \delta$ and $\phi$ measurements on chip

$T_{a b}=\frac{(1-\beta) F_{s} \cos (\alpha)}{\rho S t_{u} a_{p} \cos (\phi-\alpha)}$

with

$\beta=0,5-0,35 \log \left(R_{t} \tan (\phi)\right)$ for $0,04<R_{t} \tan (\phi)<10$ $\beta=0,3-0,15 \log \left(R_{t} \tan (\phi)\right)$ for $R_{t} \tan (\phi)>10$

and

$R_{t}=\frac{\rho S V_{c} a_{p}}{K}$

The Oxley model allows for prediction of the temperature in the secondary zone. Oxley and co-workers defined the average temperature in the secondary zone as the average temperature in the primary zone plus the maximum temperature in the chip, as defined in Eq. 9:

$T_{i n t}=T_{a b}+\psi T_{M}$

where

$\log \left(\frac{\triangle T_{m}}{\Delta T_{c}}\right)=0.06-0.195 \delta\left(\frac{R_{t} t_{c}}{l_{c}}\right)^{1 / 2}+0.5 \log \left(\frac{R_{t} t_{c}}{l_{c}}\right)$

$\delta$ is a proportion to the thickness of the secondary zone and the chip thickness. Oxley determined an iterative procedure that calculates the value based on his model and material constitutive laws. Ozel also defined an iterative procedure based on measured cutting forces and hydrostatic stress differences at points $m$ and $n$. It is also possible to measure on the chips as shown in Fig. 12.

The average temperature rise in chip, $\Delta T_{c}$, is defined as

$\triangle T_{c}=\frac{F_{f} \sin \phi}{\rho S t_{u} a_{p} \cos (\phi-\alpha)}$

where

$F_{f}=F_{c} \sin \alpha+F_{t} \cos \alpha$

Oxley defined the chip contact length according to the workpiece material constants, the cutting conditions, and the cutting process. However, based on experimental observations, Wagner developed a more accurate model for cutting chip length based on uncut chip thickness and experiments ([2]) (Eq. 13).

$l_{c}=3,57 t_{c}-0,52$

Oxley's model has been developed for orthogonal cutting. However, all experiments were performed using cylindrical operation. To simplify the study, all values are expressed in orthogonal cutting (Fig. 13).

Oxley purposed to develop a model for oblique cutting. The cutting force components and the edge inclination angles are assumed to be independent. Based on experimental observation, the chip flow direction satisfies Stabler's flow rule. The cutting force components $\left(F_{c}\right.$ and $\left.F_{t}\right)$ are defined using Oxley's thermomechanical model with a modified rake angle $\left(\alpha_{n}\right)$. The radial component $\left(F_{r}\right)$ is defined by assuming that the cutting force is situated in an orthogonal plane to the rake face, where the friction force is located (Eq. 14). The friction force and the chip velocity are also collinear :

$F_{r}=\frac{F_{c}\left(\sin \lambda_{s}-\cos \lambda_{s} \sin \alpha_{n} \tan \eta_{c}\right)-F_{t} \cos \alpha_{n} \tan \eta_{c}}{\sin \lambda_{s} \sin \alpha_{n} \tan \eta_{c}+\cos \lambda_{s}}$

With a nonzero side-cutting edge angle, the force components $F_{t}$ and $F_{r}$ do not act in the feed and radial direction. Therefore, it is possible to define the cutting force components as:

$$
\begin{gathered}
F_{x}=F_{c} \\
F_{y}=F_{t} \cos C_{s}^{*}+F_{r} \sin C_{s}^{*} \\
F_{z}=F_{t} \sin C_{s}^{*}-F_{r} \cos C_{s}^{*}
\end{gathered}
$$

where

$C_{s}^{*}=C_{s}+\eta_{o}$

$\eta_{o}=\frac{\pi}{2}-C_{s}-\bar{\Omega}_{o}$ 

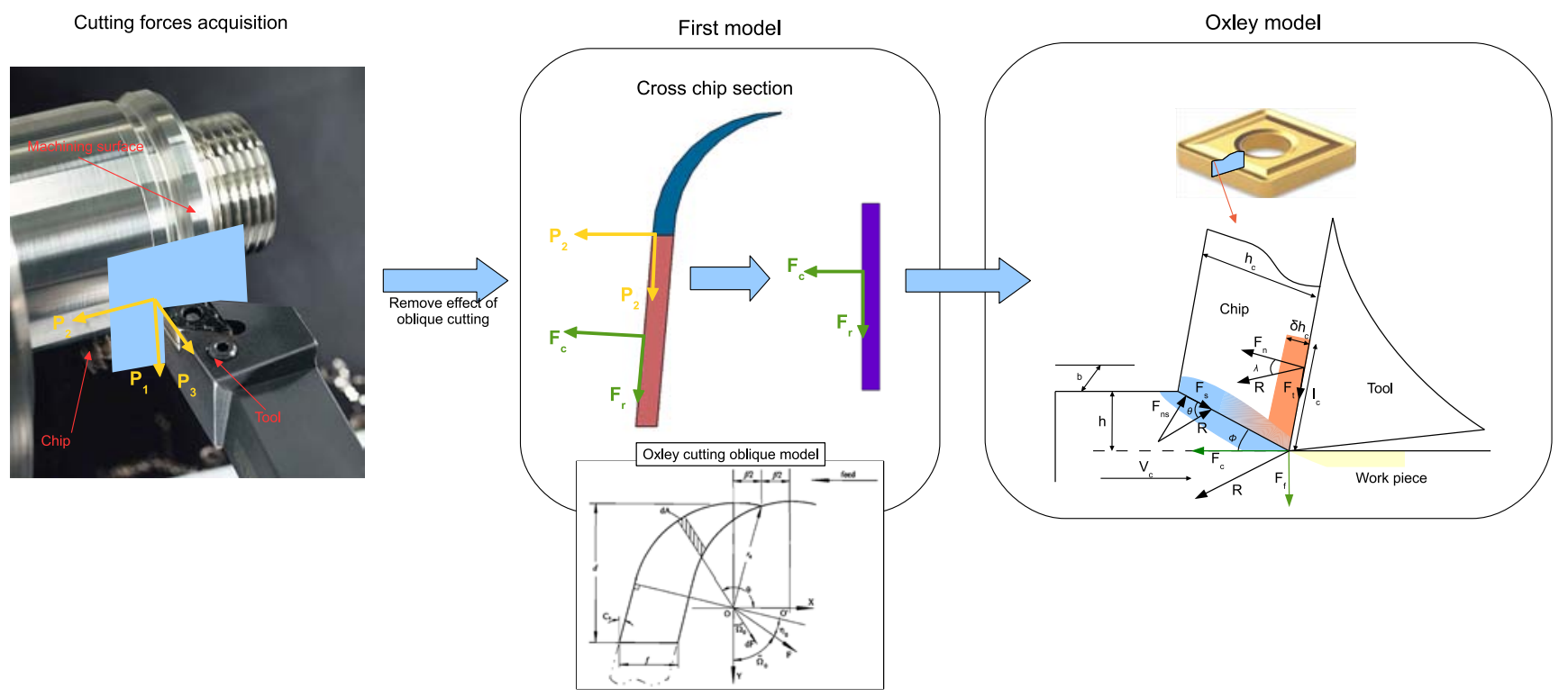

Fig. 13 Goal of the model

$\Omega_{o}=\tan ^{-1}\left(\frac{\int \sin \Omega_{0} d A}{\int \cos \Omega_{o} d A}\right)$

It also possible to define $F_{c}, F_{t}$, and $F_{r}$ using Eq. 19.

$$
\begin{gathered}
F_{c}=F_{x} \\
F_{t}=F_{y}\left(\frac{1}{\tan C_{s}^{*}}+F_{z}\right)\left(\sin C_{s}^{*}+\frac{\cos C_{s}^{*}}{\tan C_{s}^{*}}\right)^{-1} \\
F_{r}=\left(F_{t} \sin C_{s}^{*}-F_{z}\right) \frac{1}{\cos C_{s}^{*}}
\end{gathered}
$$

When using Eq. 19, the three cutting forces components $\left(F_{x}, F_{y}\right.$, and $\left.F_{z}\right)$ are expressed in a new coordinate system located on the tool insert $\left(F_{c}, F_{t}\right.$, and $\left.F_{r}\right)$ (Fig. 14). This model allows for the quantification of stress, strain, and temperature in the primary shear plane $\left(T_{a b}\right)$ and at the tool chip interface $\left(T_{i n t}\right)$ during machining (Fig. 15).
In this range, an increase of cutting speeds generates high cutting forces (Fig. 15a). This evolution is more significant when the cutting speed exceeds $55^{\mathrm{m}} / \mathrm{min}$. The model used allows for the quantification of phenomena in the workpiece material and at the tool chip interface. The cutting forces in machining are due to stresses in the primary shear plane, friction at the tool chip interface and friction at the flank face. During Ti-5553 machining, this last contribution seems insignificant because flank wear was not observed. The shear flow stress in the primary zone varied from 550 to $570 \mathrm{MPa}$ (Fig. 15b). Its contribution to the cutting forces is stable for any cutting speeds. The tests show an increase in the cutting forces at the highest cutting speeds (Fig. 15b). Consequently, the ratio between the tangential force on the
Fig. 14 Cutting force components in two coordinate systems

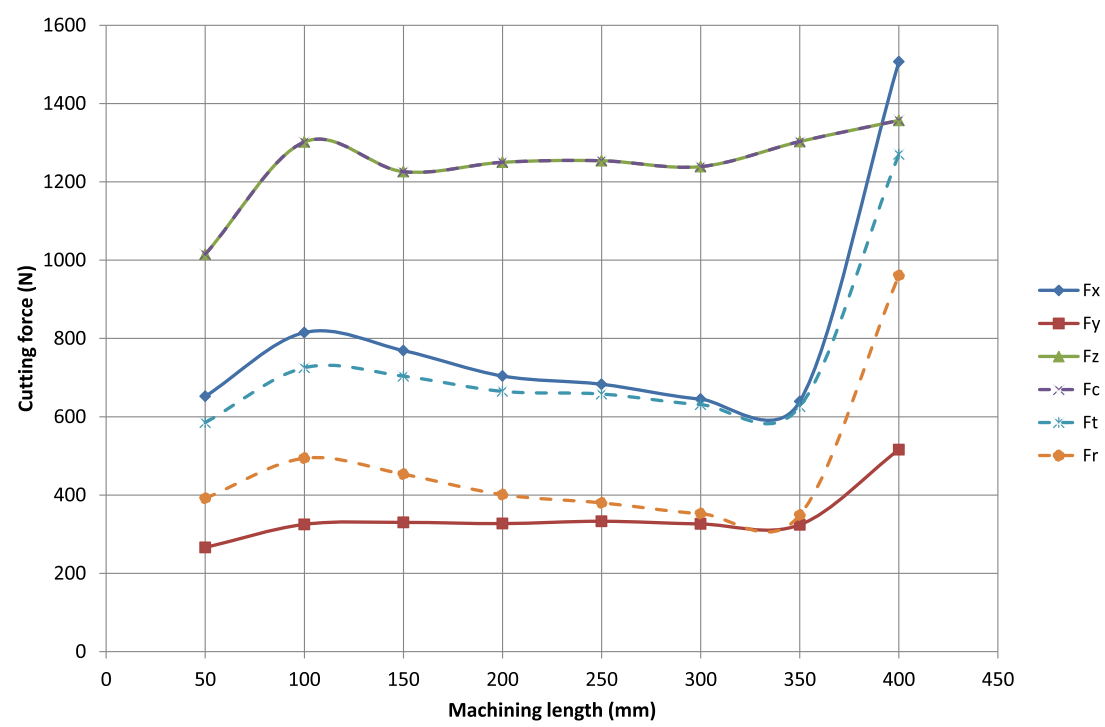


Fig. 15 Mechanical stress and cutting temperature observations
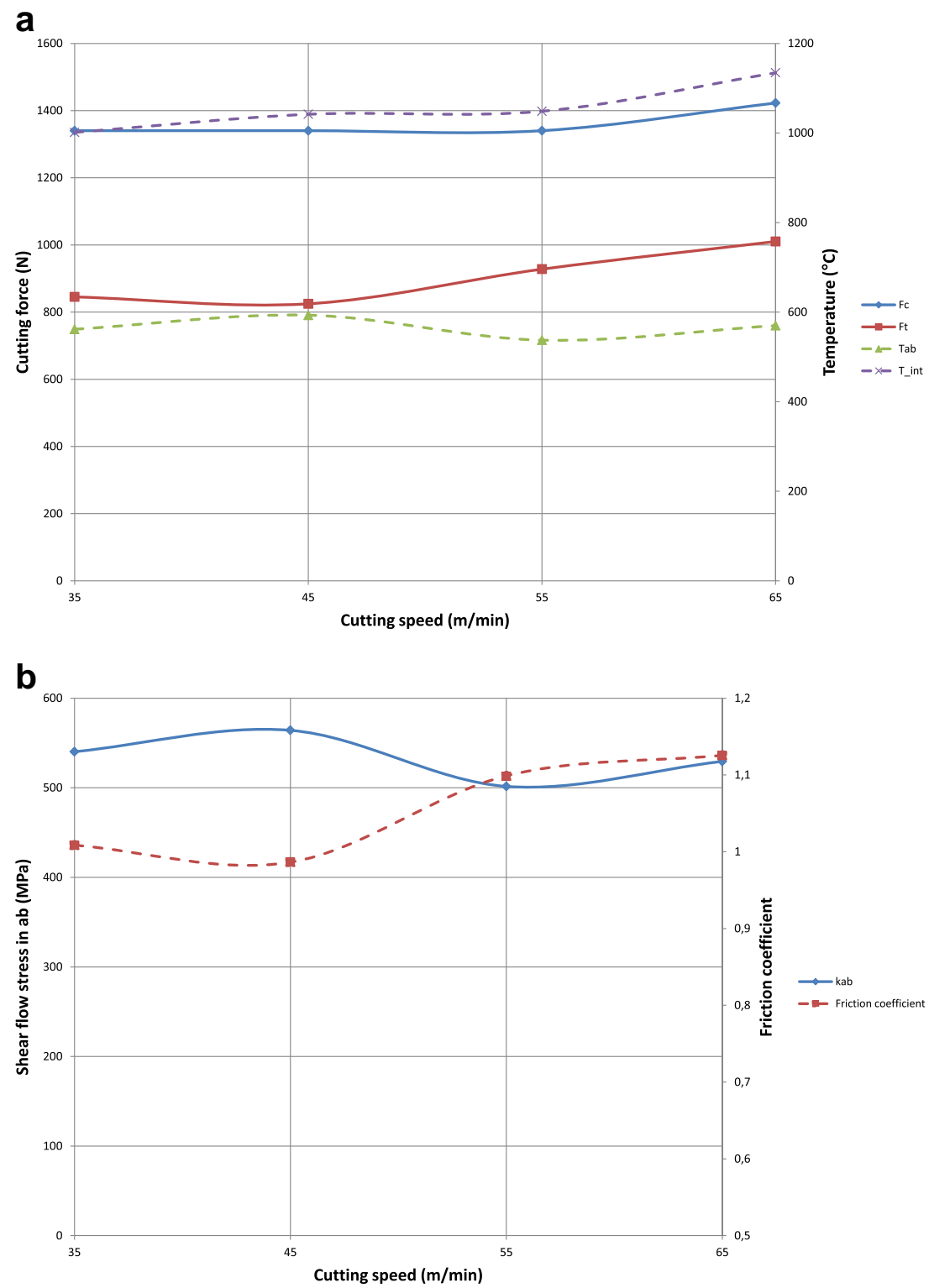

rake face and the normal forces increases. Its effect on the cutting forces raises with an increase in the cutting speed. The small change in the shear stress in the primary shear plane is due to the constant temperature $\left(T_{a b}\right)$ combined with the thermal and mechanical properties of Ti-5553 (Fig. 15a). The titanium alloys are often used for aeronautical motor rotating parts where the temperatures are high and the parts must maintain their mechanical properties ([6]). Furthermore, the low thermal property of Ti-5553 compared to the tool material limits the temperature diffusion into the workpiece ([6]). Consequently, the cutting temperature during Ti-5553 machining is high but a large portion of thermal energy is conducted into the tool. The thermal energy is, therefore, too low to result in the thermal softening observed in traditional materials. Instead of thermal softening, some machining tests have resulted in hot workpieces ([12]). The tests showed a poor reduction in the cutting forces when the workpiece temperature was below $750{ }^{\circ} \mathrm{C}$, and they attributed this behavior to the high strength of titanium alloys at high temperatures. Contrary to $T_{a b}$, there was a change in temperature at the tool chip interface, and its level was twice as high as $T_{a b}$. These high temperatures generated some adhesion, which promoted friction.

\section{Chip morphology analysis}

\subsection{Macroscopic scale}

The chip analysis can be made in different scales. As observed in Fig. 16, the chips are like nonsegmented ribbons. A surface is bright and smooth. It corresponds to 


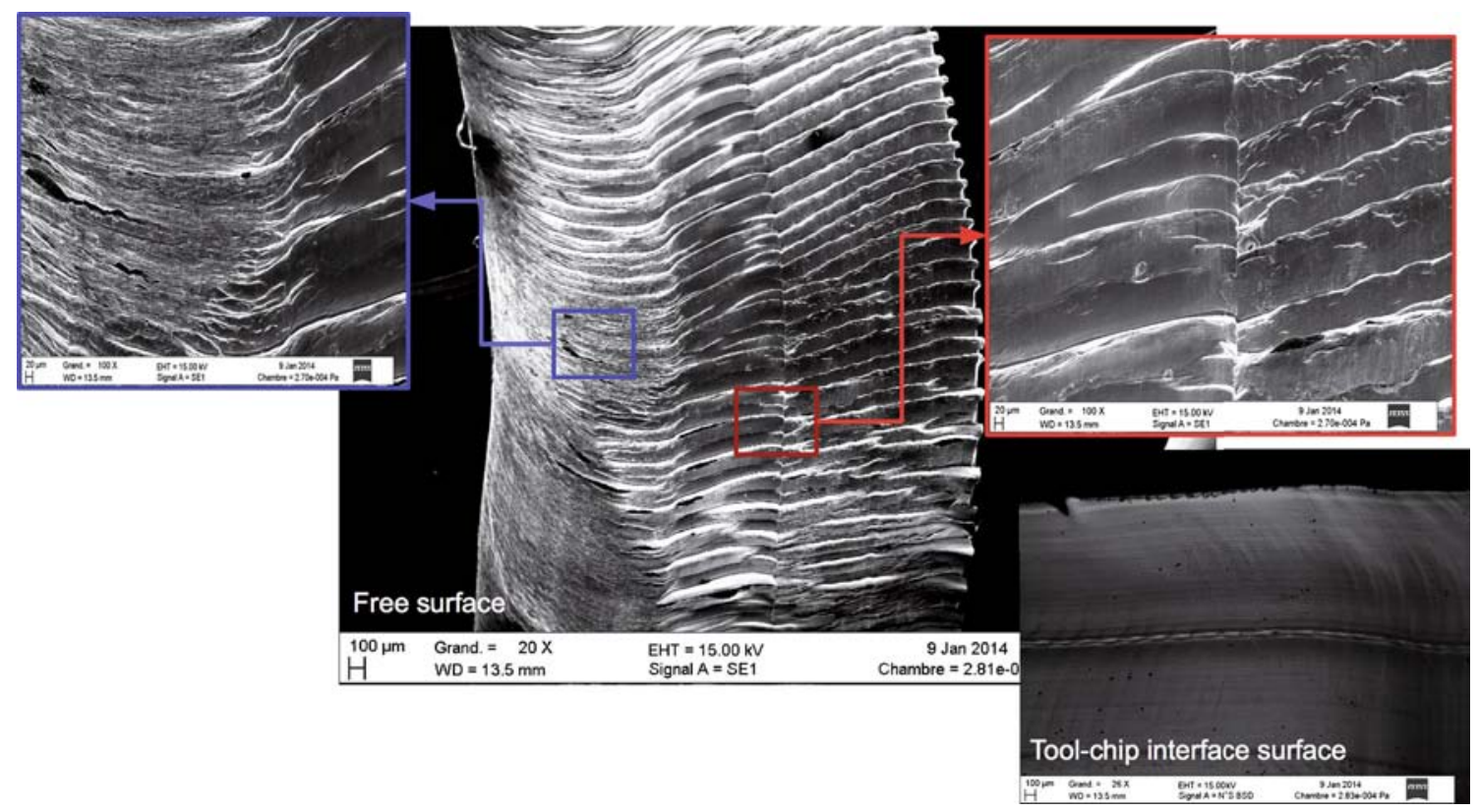

Fig. 16 Macroscopic scale of the chip

the surface that is in contact with the rake face where the chip flow was observed. The second surface is rough, some lamellae occur, and it is called the free surface. As presented in the next section, the chip formation during titanium machining is explained by the shear stress instability of uncut chips and the cutting tool geometry. The lamellas represent the upper part of the chip, where the adiabatic shear bands occur. On the free surface, two main zones

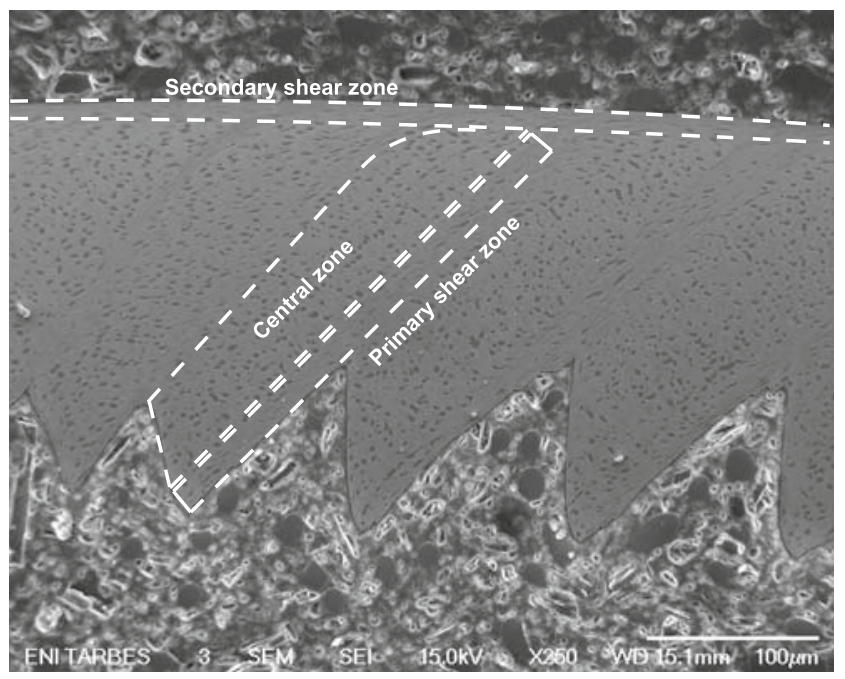

Fig. 17 Chip zones are observed. The first zone (blue rectangle to the left) corresponds to the portion of the chip formed by the nose radius. In this area, the lamellae are less distinct. This observation is due to the smallest uncut chip thickness, which occurs due to the nose radius and reduces the strain and temperature. In the second zone (red rectangle), some lamellae occur, which indicate chip formation instability. The separation observed in the middle of the red rectangle represents the limit between the chip generated by the tool nose radius and the gip formed by the straight cutting edge.

\subsection{Chip formation analysis}

Chip formation during the machining of titanium alloys has been studied for many years. Several theories have been developed and discussed. The first theory is based on the theory of catastrophic adiabatic shear. During the cutting process, most of the deformation is concentrated in the primary shear plane. A high rate of work hardening of the material develops. Moreover, most of the deformation energy is converted to heat energy. Consequently, there is a substantial increase in the temperature of the primary shear band. With this heat, the mechanical properties of the material are reduced. This phenomenon is called thermal softening. There is a catastrophic shear or adiabatic shear when the thermal softening exceeds the rate of hardening. According to the second theory, the segmented chip formation is the result of a crack initiated at the free 
Fig. 18 Primary shear zone and main zone of chip

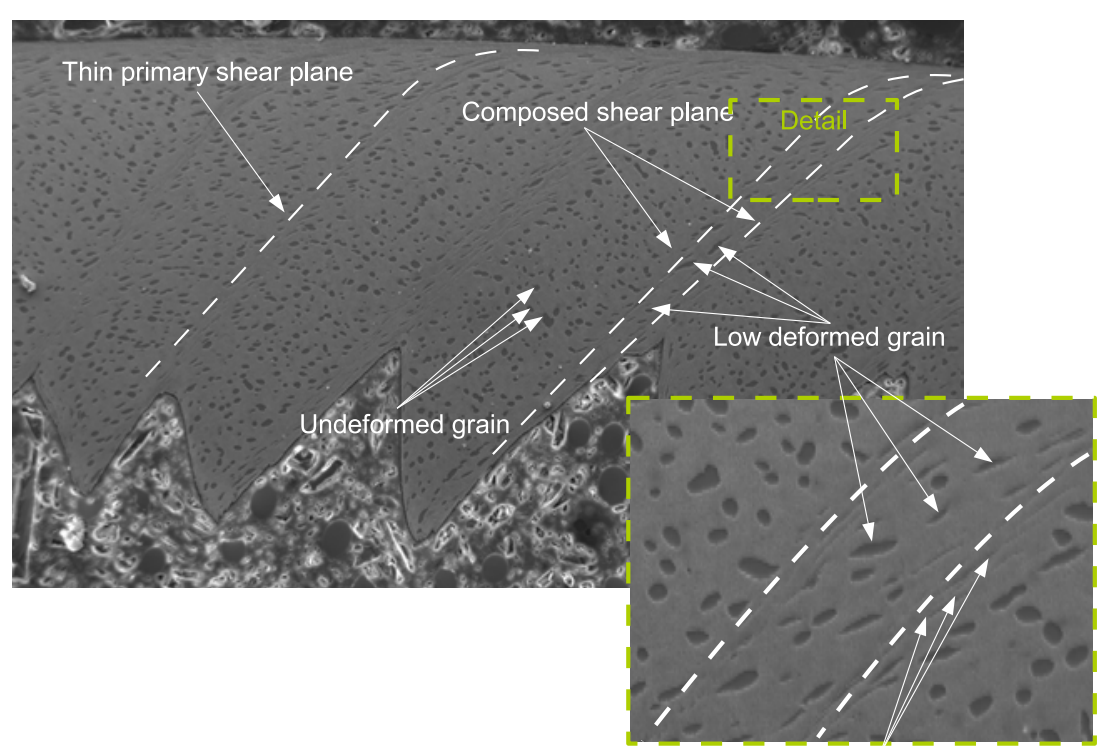

High deformed grains surface and its spread to cutting edge in the primary shear plane. Poulachon and co-workers described the chip formation for hardened steel in four successive phases ([13]). The last theory, developed and presented by [11], is based on experimental tests of Ti-64 machining. He showed a difference in chip formation during titanium alloy machining compared to steel. The first stage implicates some plastic instability and localized strain. These phenomena occur in a band situated in the primary shear plane and induce a catastrophic shear failure along a shear surface. The other stage of the chip formation involves the gradual build-up of the segments with low deformation due to the flattening of the wedgeshaped front of the advancing tool. The contact between the rake face and the segment on the cutting edge is very short in time. The segment pushes the newly formed segment, and a ribbon is formed. Despite the number of models and theories, the development of new materials with complex behaviors and the prediction of their properties and the cutting process are not always possible. The objective of this section is to verify the mode of chip formation when machining Ti-5553 using geometric and metallographic studies and the modeling proposed in the previous section. A section of this study will attempt to define some criteria for comparison of chips for the following parts.

As described by [14], a chip is divided in three zones (Fig. 17). In the first zone, some shear bands appear. They start at the base of the chip and they finish at the top of the chip serrations. A second area parallel to the length of chip occurs. In this zone, the deformation direction of the grain appears to be identical to the flow of the chip along the rake face of the cutting tool. This area is called the secondary shear zone. The last area is the center of each chip serration. In this area, the grains do not appear distorted. The deformation can be considered very low. The analysis of the chip can be made from the three areas mentioned above. The study will also examine the morphological parameters, such as the thickness of the shear bands or the frequency of occurrence of primary shear bands.

\subsection{Analysis of the chip morphology}

As observed in Fig. 18, there is a strong deformation of the $\alpha$ nodules, which indicate the deformation lines and the flow direction. The nodules are mainly deformed in two directions: the primary shear zone and the secondary shear zone. In the primary shear zone, the SEM analysis show that there are different types of primary shear zone. The first type is a thin plane where every grains seem to be deformed in the same direction. Concerning the secondary geometry, the primary shear zone is not a plane. As observed in Fig. 17, two distinct planes appear at the base of the chip. These two lines join at the end of the serration of the chip. This secondary geometry generally appears for the greatest height of chip serration. Nonlinear movement highlights the relative motion between the already formed chip and the segment that is being formed. The composed shear plane can be due to the high level of 
Fig. 19 Chip formation during titanium machining ([11]) and during Ti-5553 machining
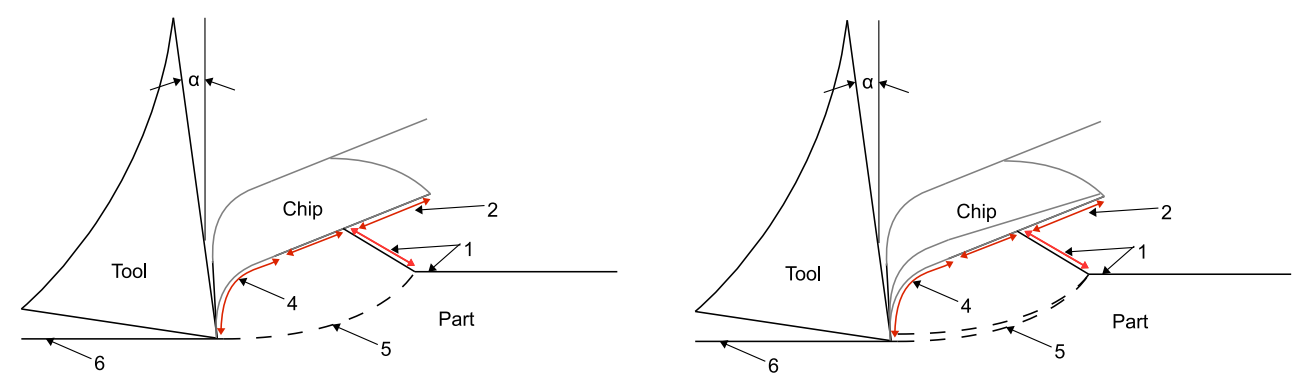

deformations and the heterogeneity of the Ti- 5553 . When the tool advances, some intense localized deformations occur in front of the cutting edge. Because of the presence of $\alpha$ grains and the resulting heterogeneity, two very close shear bands are crated. The chip is generated based on these two shear bands.

All primary shear zones start at the chip base with approximately the same radius when the cutting tool geometry is unchanged. In the main zone of the chip, the grains do not appear deformed and show the lowest level of stress and strain. The curvature of the primary shear plane is explained by the chip formation, as explained in Fig. 19 where various surfaces occur; (1) represents the undeformed surface of a chip. As observed in Fig. 18, the $\alpha$ grains are always circular in this zone and show very low deformation; (2) is the $\alpha$ section of the primary shear plane. This zone is a part of the catastrophic shear zone, which is separated from the previous segment. Figure 18 shows the high deformation of the $\alpha$ grains, which occur at the end of the segment; (3) is the zone where an intense shear band is formed by catastrophic shearing during the failure stage of the segment formation; (4) is the zone in contact with the rake face where some intense shearing occurs; and (5) is the primary shear plane where some intense localized deformations appear. As described by [11], the primary shear plane is curved; (6) is the machined surface.

Figure 20 clearly shows the deformation phenomenon inside the workpiece material microstructure during the chip formation. The deformations and flow can be observed with the $\alpha$ nodules, but some deformations also occur in the $\beta$ matrix, where some $\alpha$ lamellae are observed. Indeed, as shown in Fig. 20, the lamellae are also deformed in the flow direction. However, there is a large difference between the two shear zones. In the first shear zones, the lamellae are oriented in the flow direction. Their densities seem stable, except near the $\alpha$ nodules, where they appear degraded. In the secondary shear zone, the lamellae disappear, which results in a homogeneous material. Thus, two ways are conceivable. After machining, the material is hardened and heated in the two shear zones and at different levels. The temperature and the strain in the primary shear plane and

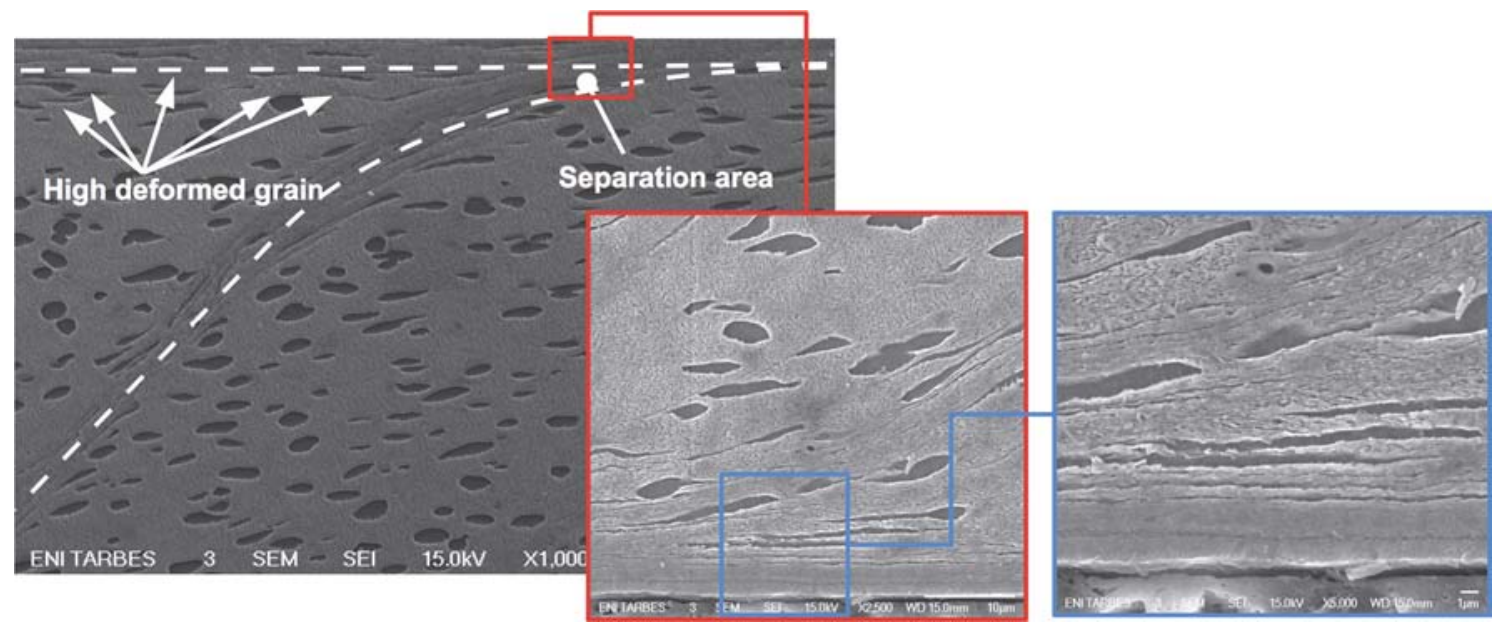

Fig. 20 Second shear zone 


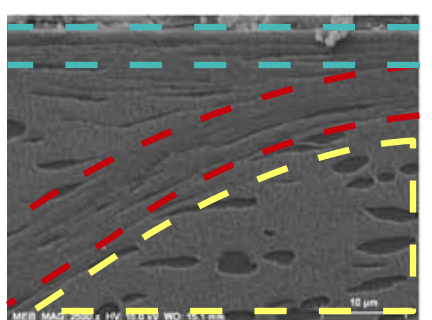

(a)

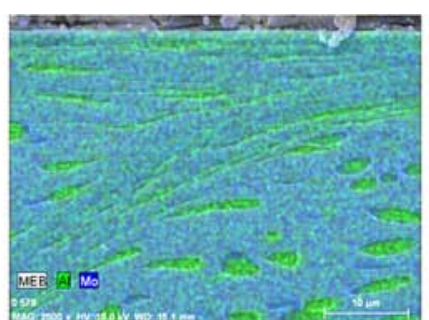

(b)

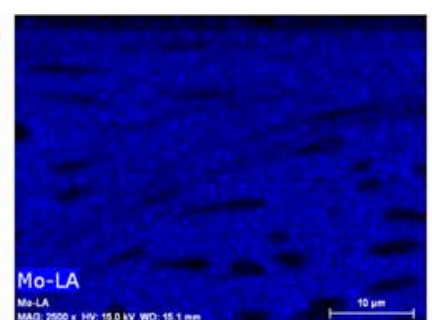

(c)

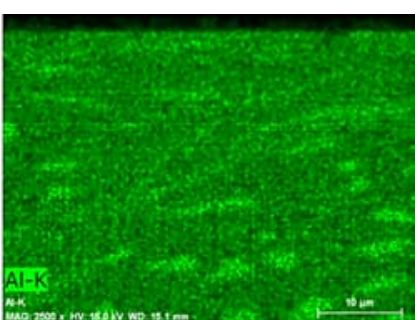

(d)

Fig. 21 Material analysis of both zones

at the tool chip interface can be calculated using the model presented in the previous section where $V_{c}=45^{\mathrm{m}} / \mathrm{min}$, $T_{a b}=593^{\circ} \mathrm{C}$, and $T_{i n t}=1041^{\circ} \mathrm{C}$. The highest temperature and the highest strain are observed in the second shear plane. In the primary shear zone, the temperature is always under $\beta$-transus $\left(T_{\text {beta }}=880^{\circ} \mathrm{C}\right)$. Because of the significant hardening, this mechanical stress may generate high deformations of all lamellae in the same direction. During machining, this direction is parallel to the chip axis or the rake face. However, high temperatures are also observed at the tool chip interface. This heat input could induce some dissolution of lamellae, which can partially explain their modifications.

Figure 21 shows the molybdenum concentration (c), aluminum concentration (d), and the both material concentration (b) in the primary and secondary shear zones. As defined in the previous section, the Ti-5553 titanium alloy is composed of two phases after forging and heat treatment. In the primary zone of a chip, the material is not subjected to high stresses or heats. The alloy can be considered in its initial state; the concentrations of molybdenum and aluminum are identical to the initial concentrations. The grains are deformed, but in the primary shear zone, the aluminum concentration remains stable. This very low concentration is partially due to the thermal properties of Ti-5553. Tint is higher than the $\beta$-transus temperature, but the difference in the thermal properties of the cutting tool material and titanium generates heat transfer into the tool. Consequently, the temperature in the material is just below the $\beta$-transus temperature, and the material is not modified. Moreover, a modification of the chemical composition generally occurs when the alloy is stabilized. During machining, the thermal and the mechanical phenomena generally occur. Consequently, the composition and the structure are unchanged.


Fig. 22 Evolution of chip morphology and cutting temperature with cutting speed 

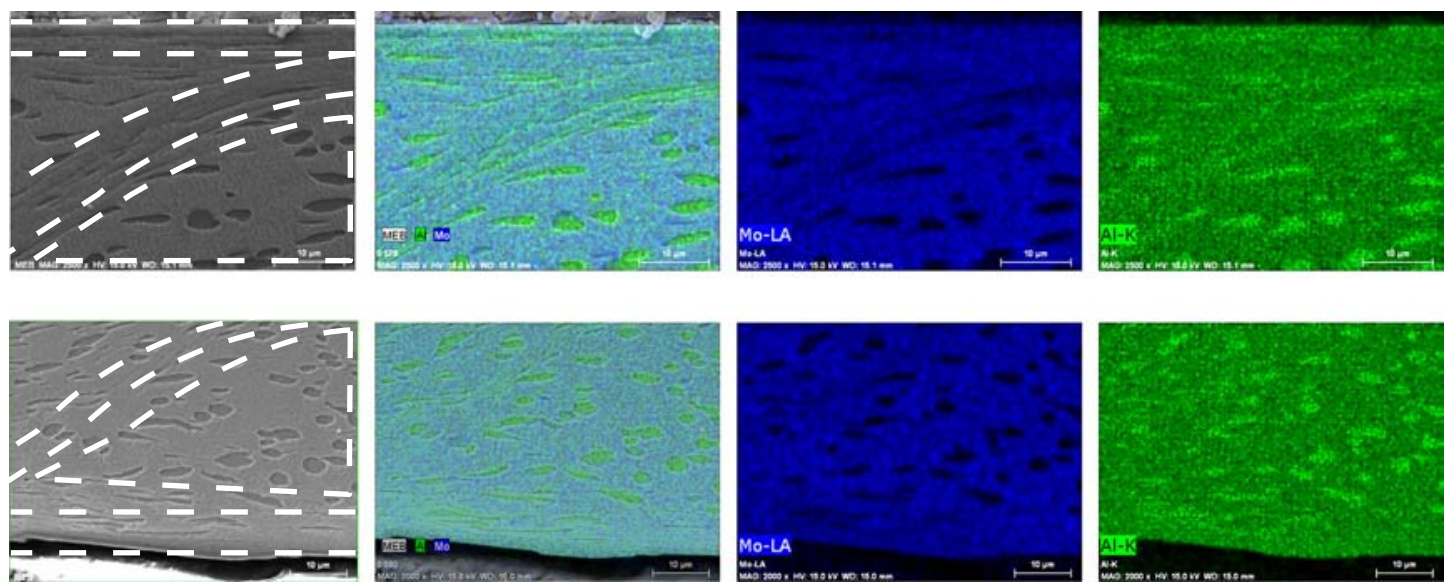

Fig. 23 Evolution of workpiece material with the cutting speeds

6.4 The effect of the cutting speed effect on the chip morphology

Figure 22 presents the evolution of the chip morphology, cutting temperatures, and chip geometry as a function of the cutting speed. As observed previously, the cutting speed influences the cutting temperature inside the workpiece material and at the tool chip interface. However, its effect on chip formation is unknown. At first, for any cutting conditions, the chips are always classified as serrated type. Consequently, the cutting process seems unchanged due to the mechanical and thermal properties of Ti-5553. Indeed, the temperature during machining in the primary shear plane varies from 570 to $600{ }^{\circ} \mathrm{C}$. As observed during mechanical tests and as demonstrated by [2], the mechanical properties are stable when the temperature is below $800{ }^{\circ} \mathrm{C}$ and the chip formation is unchanged.

From the point of view of the chip geometry, it appears that the increase in cutting speed has a slight effect. The maximum chip thickness is reduced at the highest cutting speeds. The same evolution is observed for the minimum thickness. The reduction in the minimum thickness induces an increase in the chip segmentation and can favor the effect of a high-pressure lubricant. The shear angle is affected by the cutting speed. For all cutting speeds tested, it appears that the shear angle increases when $V c=55^{\mathrm{m}} / \mathrm{min}$ and decreases for $V_{c}=65^{\mathrm{m}} / \mathrm{min}$.

Figure 23 presents the evolution of the workpiece material in the primary and secondary shear plane at two cutting speeds (35 and $65^{\mathrm{m} / \text { min }}$ ). The alloy composition is not altered at either cutting speed. However, as described previously, the cutting temperature is higher than the $\beta$-transus temperature. The cutting speed effect is higher at the tool-chip interface where the temperature is above the $\beta$-transus temperature. However, with increasing cutting speed, the alloy composition is not altered in all shear zones.

\section{The effect of cutting conditions on tool wear and cutting process}

In this section, some tests were made where the cutting forces were measured over $50 \mathrm{~mm}$. Each value represents the mean value of the test. Figure $24 \mathrm{~b}$ shows the evolution of the tool life in seconds as a function of the cutting speed. The length of machining is represented in Fig. 24b. The longest tool life is obtained when $V_{c}=35^{\mathrm{m}} / \mathrm{min}$ and the shortest tool life occurs with $V_{c}=65^{\mathrm{m}} / \mathrm{min}$. An $50 \%$ increase in the cutting speed decreases the machining length by $20 \%$. However, it is important to understand the relationship between tool life and machining length. Indeed, for the same increase in cutting speed, the tool life decreases by $20 \%$. To conclude, the highest cutting speed allows the fastest material removal rate for the same tool but results in a shorter tool life. The cutting speed modifies the strain rate and consequently the cutting forces, the cutting temperatures, and the flow on the rake face.

To define the effects of the cutting speed and tool wear on the cutting process, the previously described model has been used to define the temperature in the workpiece material and at the tool chip-interface and the friction coefficient (Fig. 25). To adjust the cutting tool geometry for each test, the cutting tool geometry has been measured using the 
Fig. 24 Cutting speed effect on cutting length (a) and tool life (b)
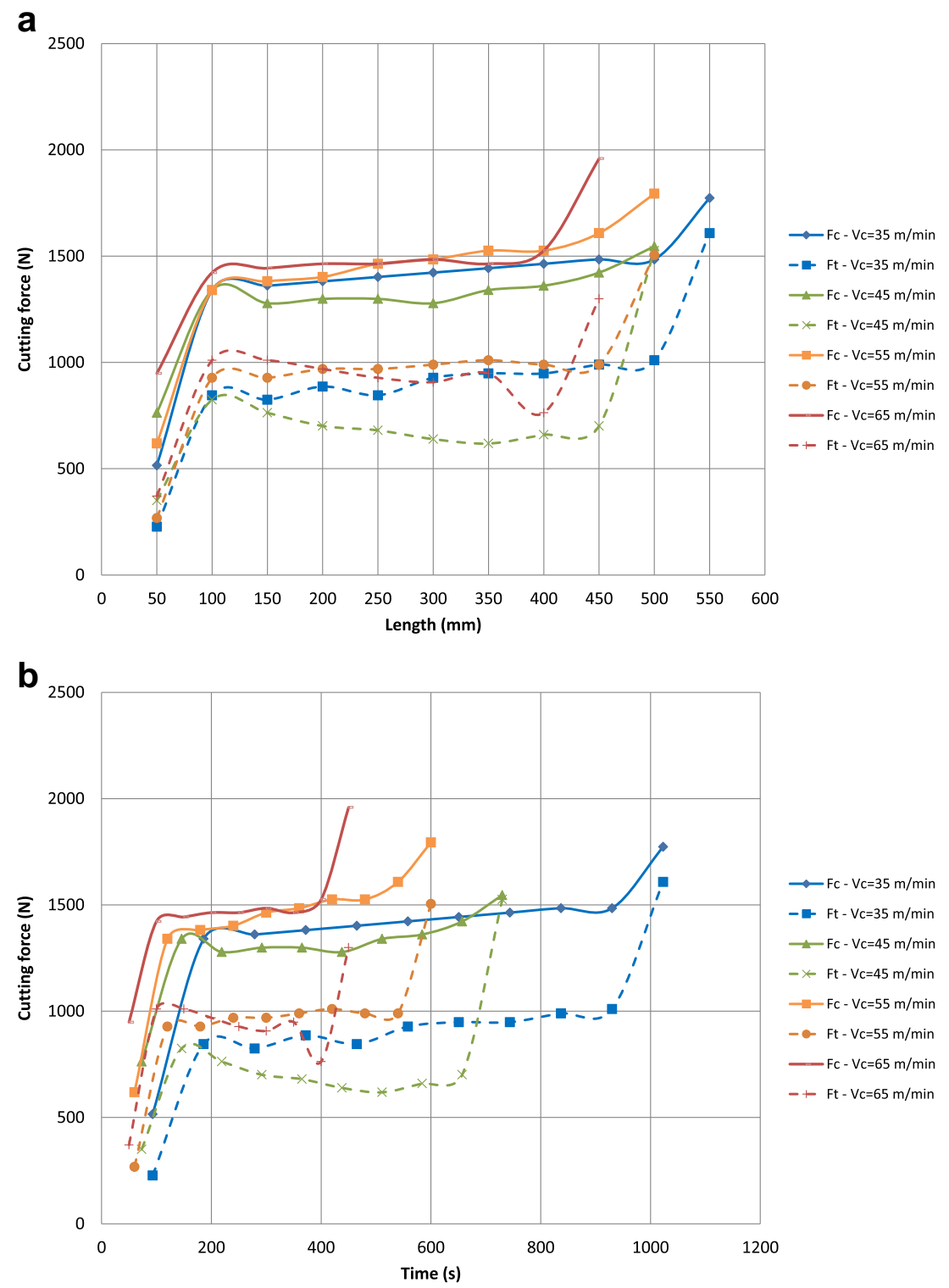

optical interferometry technique. These observations show the evolution of the rake angle with the tool wear. At first, the cutting temperatures increase with the tool wear. The highest increase is always observed for the last test when the cutting tool geometry is damaged. These deteriorations (built-up edges and abrasions) partially explain this temperature evolution. The major increase is observed at the tool chip interface because the tool wear occurs on the rake face. The small change in the temperature in the primary shear plane is due to the Ti-5553 thermal properties, which does not change in this range of temperatures. The evolution of the friction is similar to the temperature at the tool chip interface. The highest cutting temperatures can also be observed through the chip colors. Indeed, the $\mathrm{TiO} 2$ thickness changes with temperature and influence the titanium color [15]. After the first test, the chip color is unchanged. The color of the chips changes from gray to gold and then yellow. At higher temperatures, where the oxide layer is the most important feature, the chips are blue-purple.

\section{The relationship between the tool wear and chip morphology}

As observed in Fig. 26, the chip formation is affected by the tool wear and its effect on the cutting tool geometry. 
Fig. 25 Cutting temperature in the primary shear plane and at the tool chip interface and friction at the tool chip interface as a function of tool wear

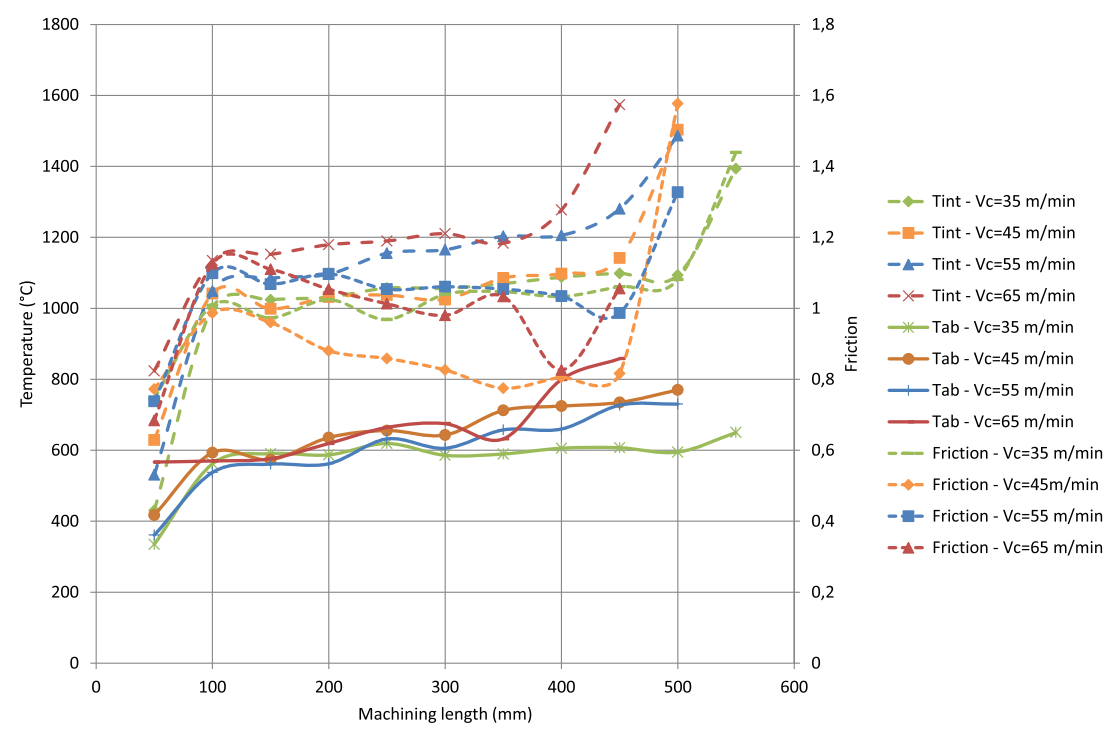

At first, the type of chip does not depend on the tool wear. For any tool wear, the chips collected are often categorized as regular serrated chips. However, the chip geometry is modified. After the first test, the chip geometry is constant and the frequency of the teeth formation unchanged. It should be noted that the thickness of the second shear zone is the lowest. When the wear begins on the tool, the geometries of the chips are changed. As previously explained, the formation of segments in the chips is performed along several shear planes. They start at the bottom of the chip base (second shear zone), and they join at the top of the chip. These phenomena appear cyclically and

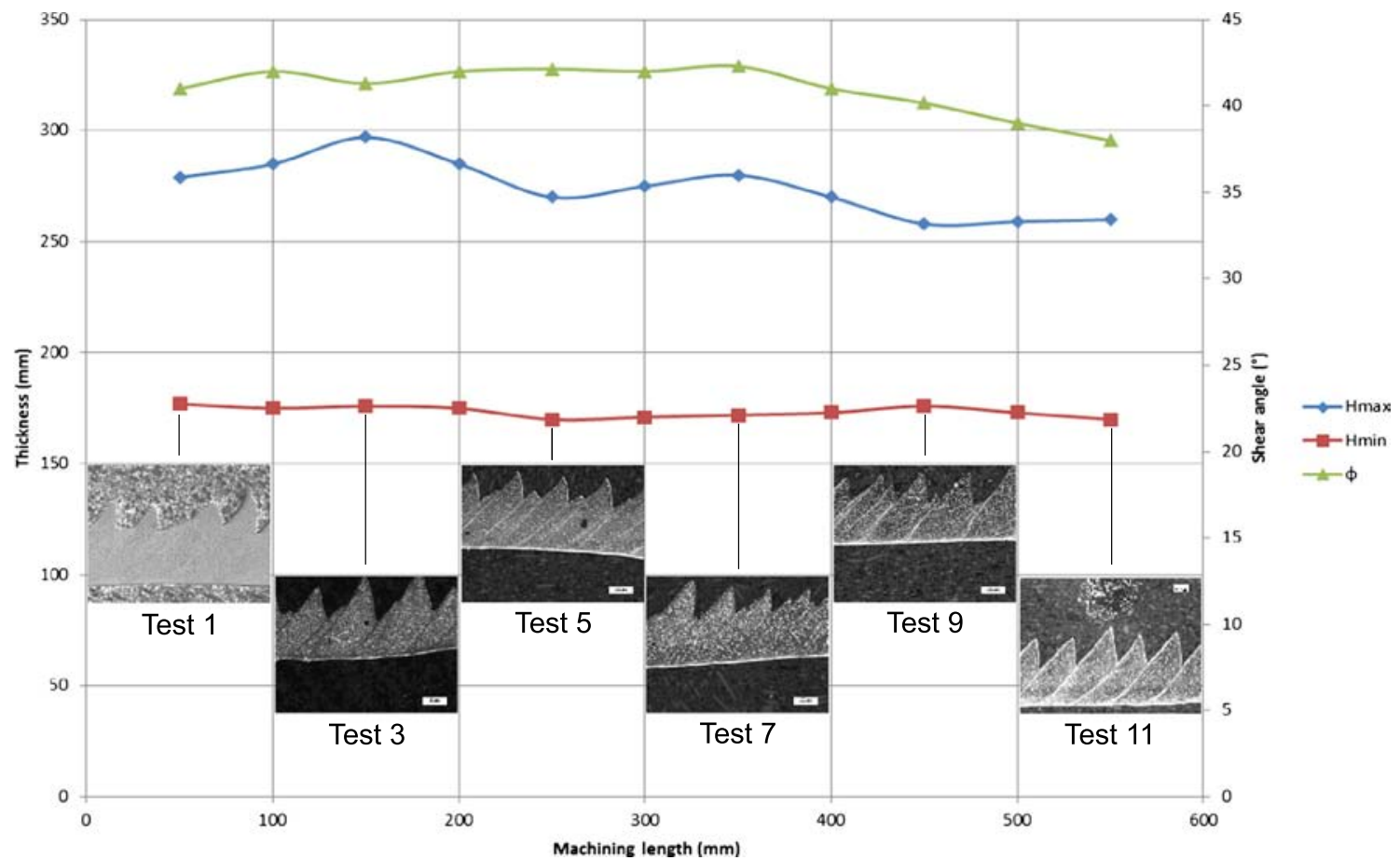

Fig. 26 Evolution of chip morphology and tool wear 


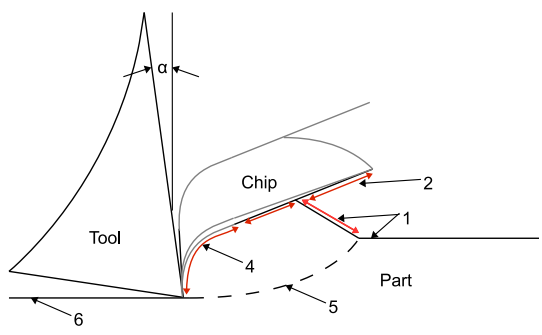

(a)

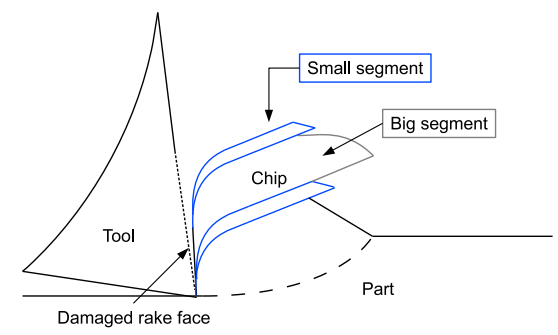

(b)

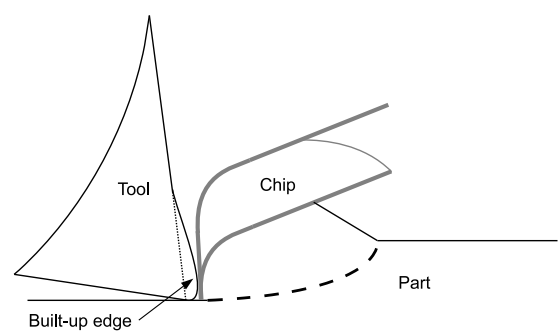

(c)

Fig. 27 Evolution of chip formation with tool wear

periodically. As shown in Fig. 27, the dynamic chip formation is modified when the tool is worn. The resulting chips are composed of two types of segments. For the first type of segment, its geometry is identical to the chips obtained in the previous tests, and a second type of segment is always inserted between the two segments. As described previously, the primary shear plane is composed of two very close shear bands, which can be due to some workpiece material heterogeneity. When the tool is worn, as observed in the previous section, the temperature increases and due to the cutting tool geometry, the deformation increases. The intense localized energy increases close to the apex of the tool and is sufficient to generate the segments. When a BUE or an edge failure occurs, the chip formation is completely changed. Indeed, the two types of segment disappear. One type of segment is generated, but the thickness of the shear bands increases. The thermal and the mechanical energies are also enough to generate one type of segment as described by [11].

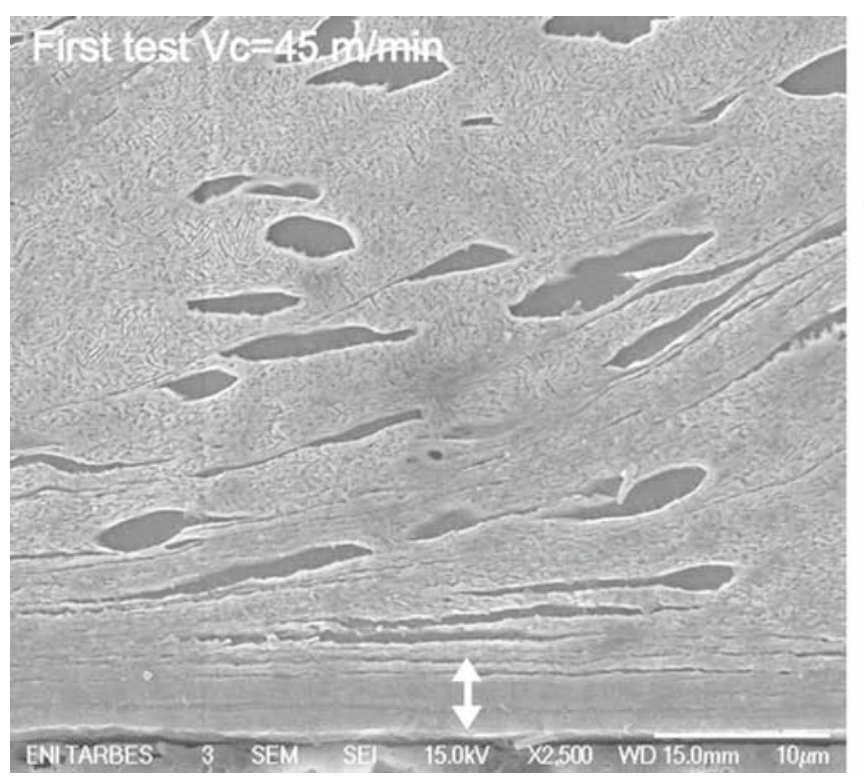

The maximal thickness and the minimum thickness reduce as the tool wear increases. Finally, the last chip collected in test 11 is composed of identical segments. The second type of segment (smaller segment) becomes thinner until it disappears. When the tool is worn, the chip thickness is the lowest and the shear angle is the highest. During last test, a built-up edge (BUE) appears and consequently the cutting tool geometry is changed. Initially, the rake angle is $12^{\circ}$, but due to the BUE, it becomes approximately $0^{\circ}$. Consequently, the stresses are higher and crack propagation is promoted. During the tool wear tests, the chip thickness decreases while the shear angle increases.

A more detailed analysis shows the small change in chips at the tool chip interface despite the high cutting temperature and friction. The chemical analysis does not show any change in the composition (Fig. 28). As described previously, the number of deformed $\alpha$ grains increases when the tool is worn.

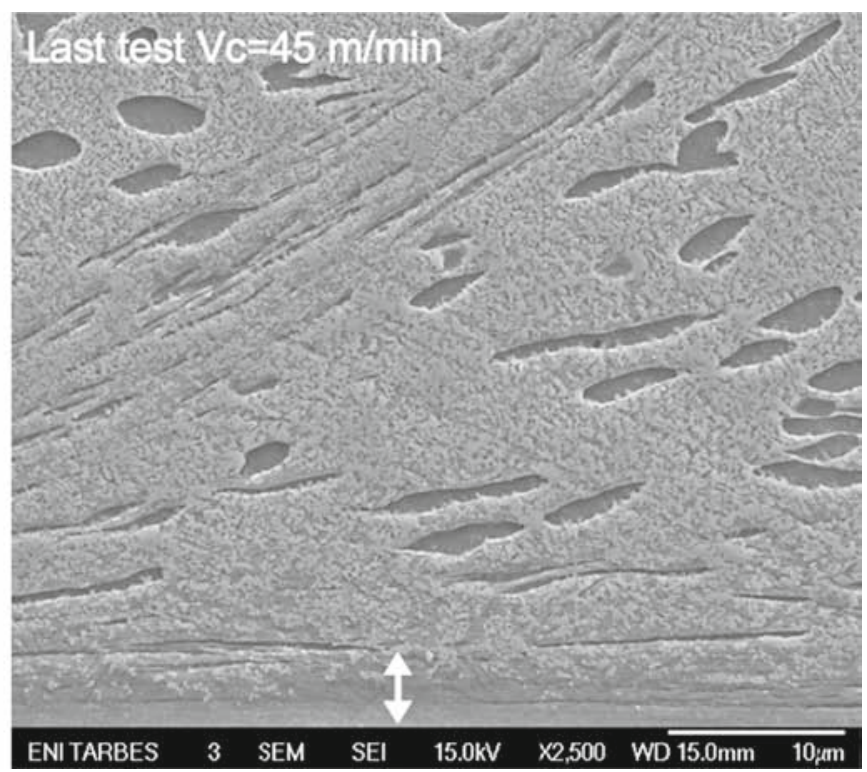

Fig. 28 Evolution of the secondary shear zone 


\section{Conclusion}

The first part of this work is devoted to presenting the mechanical and physical properties of the Ti-5553 alloy. From a physical standpoint, it is easy to classify titanium alloys in the same family. From a mechanical standpoint, titanium alloys are different. Indeed, a significant difference between Ti-64 and Ti-5553 is shown.

Concerning the tool wear, the tests highlight the stages of tool degradation before its failure. Three stages are identified in the degradation process: the first mode, normal wear, and the last mode are the succession of edge build up and edge breakdown.

A model has been used to quantify the temperature, the shear stress, and the friction. This work shows some very high temperatures, especially at the tool chip interface, as a function of cutting speed. These high temperatures are mainly due to the low thermal properties of Ti-5553 and its high mechanical properties.

The same phenomena as Ti-64 chip formation have been observed for Ti-5553 chip formation. The chips are always qualified as regular serrated chips for any cutting speed. A chemical analysis shows some small change in its composition. It is interesting to note that the Ti-5553 microstructure change due to the high levels of stress and temperature generated by the cutting process.

The last part of this work is the relationship between the chip formation, the cutting process, and the chip formation. The model developed in the previous part is used to define the temperature and the friction during each tool wear test. The temperatures and the friction at the tool chip interface increase as the tool wear increases because of the degradation of the tool. However, despite these modifications, the chip formation appears unchanged. However, the high temperature and friction must generate some change in the microstructure as phase coalescence was not observed in this work.

\section{Nomenclature}

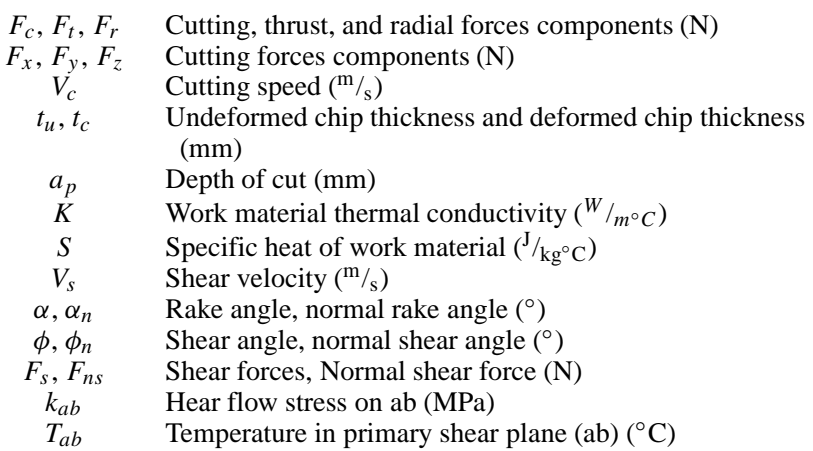

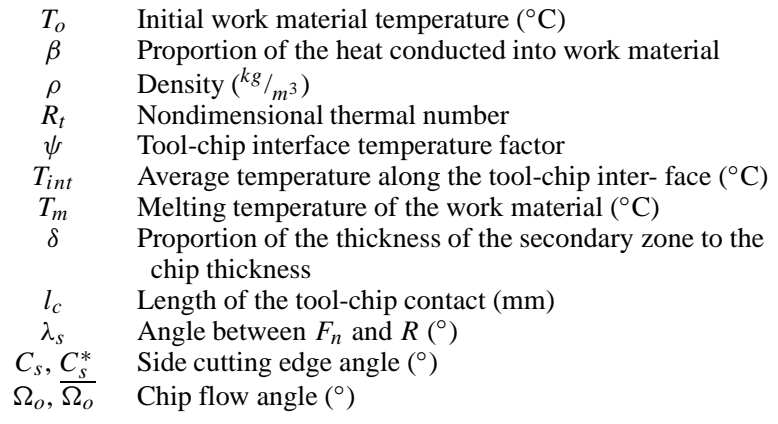

Acknowledgments The authors would like to express their thanks to Mr Jean-Yves Gendron and Mr Daniel Lallement from Messier Bugatti Dowty Bidos (France) for his support during this experimental works.

\section{References}

1. Arrazola P, Garay A, Iriarte L, Armendia M, Marya S, Le Maitre F (2009) Machinability of titanium alloys (ti6al4v and ti555. 3). J Mater Process Technol 209(5):2223-2230

2. Wagner V (2011) Improvement of productivity in machining of refractory titanium: the ti5553 titanium alloy, Ph.D. thesis, Universite de Toulouse

3. Ezugwu E, Wang Z (1997) Titanium alloys and their machinability-a review. J Mat 68:262-274

4. Min W, Youzhen Z (1998) Diffusion wear in milling titanium. Materials science and technologies 4:548-553

5. Perez J, Llorente J, Sanchez J, et al. (2000) Advanced cutting conditions for the milling of aeronautical alloys. J Mater Process Technol 100(1):1-11

6. Dearnley P, Grearson A (1986) Mater Sci Technol 2:47-58

7. Fang N, Wu Q (2005) The effects of chamfered and honed tool edge geometry in machining of three aluminum alloys. Int J Mach Tools Manuf 45(10):1178-1187

8. Wagner V, Baili M, Dessein G, Lallement D (2011) Experimental study of coated carbide tools behaviour: application for ti-5-5-5-3 turning. Int J Mach Mach Mater 9:233-248

9. Ozel T, Altan T (2000) Determination of workpiece flow stress and friction at the chip-tool contact for high-speed cutting. Int J Mach Tools Manuf 40(1):133-152

10. Oxley P (1989) Mechanics of machining: an analytical approach to assessing machinability. Ellis Horwood Limited(UK) 1989:242

11. Komanduri R (1982) Some clarifications on the mechanics of chip formation when machining titanium alloys. Wear 76(1):1534

12. Boothroyd G, et al. (1963) Temperatures in orthogonal metal cutting. Proc Inst Mech Eng 177(1):789-810

13. Poulachon G, Moisan A (1998) A contribution to the study of the cutting mechanisms during high speed machining of hardened steel. CIRP Ann Manuf Technol 47(1):73-76

14. Puerta Velasquez J, Bolle B, Chevrier P, Geandier G, Tidu A (2007) Metallurgical study on chips obtained by high speed machining of a ti-6wt.\% al-4wt.\% v alloy. Mater Sci Eng: A 452:469-474

15. Velten D, Biehl V, Aubertin F, Valeske B, Possart W, Breme J (2002) Preparation of tio2 layers on cp-ti and ti6al4v by thermal and anodic oxidation and by sol-gel coating techniques and their characterization. J Biomed Mater Res 59(1):18-28 